\title{
PLATAFORMA CEREMONIAL USHNU INCA DE CHENA, VALLE DEL MAIPO, CHILE
}

\author{
THE INCA USHNU CEREMONIAL PLATFORM OF CHENA, \\ MAIPO VALLEY, CHILE
}

\author{
Rubén Stehberg 1
}

\begin{abstract}
Se presentan los resultados obtenidos en las excavaciones arqueológicas de un sector con estructuras monticulares emplazadas en el extremo SE de la plaza intramuros del pucará de Chena, a $638 \mathrm{msm}$. El objetivo es identificar el origen y función de esta instalación y someter a contrastación una hipótesis planteada por distintos investigadores, respecto de que en dicho lugar la ocupación Tawantinsuyu (Inca) emplazó un sitio ceremonial importante. Los trabajos de campo permitieron descubrir los restos de la estructura interna de roca y tierra de una plataforma arquitectónica de forma cuadrangular de 6,5 x 6,5 m y 0,70 m de altura, aproximadamente, con una rampa posterior del mismo material y evidencias de un agujero central. Entre los restos muebles recuperados destacaron piedras rodadas pequeñas, seis bolones grandes, restos de toba y azufre y fragmentos de camélidos, malacológicos y cerámicos, todos del período incaico. Estos últimos fueron fechados por termoluminiscencia proporcionando dos dataciones coherentes: 1490 y 1505 d.C. Los restos encontrados guardaron similitud con hallazgos encontrados en ushnus con plataforma ceremonial existentes en las principales plazas y centros administrativos a lo largo del Tawantinsuyu, lo cual apoya la hipótesis que los restos de Chena correspondieron a una instalación de este tipo. Se constituyó así en la plataforma ushnu conocida más austral del estado inca.

Palabras claves: plataforma ceremonial, ushnu, Chena, período Tawantinsuyu, valle del Maipo.
\end{abstract}

The results of the archaeological excavations of a sector with mound structures located on the SE edge of the square intramural Chena Pucara are presented. The aim is to identify the origin and function of this facility and submit contrasting hypotheses raised by various researchers mentioning that in this place the Tawantinsuyu (Inca) established an important ceremonial site (ushnu). Fieldwork have uncovered the remains of the internal structure of rock and dirt of an architectural quadrilateral platform of 6.5 $x 6.5 \mathrm{~m}$ and $0.70 \mathrm{~m}$ in height approximately, a rear ramp, the same material and evidence of a central hole. Among the remains recovered were small loose rocks, six large boulders, remains of tufa and sulfur and fragments of camel, malacological and ceramics, all of the Inca period. The latter were dated by thermoluminescence providing two coherent dating: 1490 and $1505 \mathrm{AD}$. The remains proved to be similar to findings in ushnus with existing ceremonial platform in the main squares and administrative centers along the Tawantinsuyu, which supported the hypothesis that the remains of Chena corresponded to a facility of this type. It became the southernmost platform of the Tawantinsuyu.

Key words: Ritual platform, ushnu, Chena, Tawantinsuyu period, Maipo valley.

Actualmente se postula una muy marcada ocupación Tawantinsuyu para los valles de Mapocho-Maipo, en momentos inmediatamente anteriores al arribo europeo a la zona de Chile central (1536 y 1540). El alto interés incaico por controlar estos dos valles radica en su posición estratégica al constituirse en la cabecera y puerta de entrada y salida de la depresión intermedia o llano central, territorio fértil y poblado que se extiende por casi 1000 kilómetros hacia el sur. Es factible que esta circunstancia haya influido de manera significativa en la población local tardía preinca (Cultura Aconcagua), al tener su residencia en un espacio de alto flujo de personas, bienes e ideas, que les permitió tener contacto con otras culturas, acelerando su proceso de andinización y, al mismo tiempo, reforzando su sentido de identidad, como se observa en sus patrones mortuorios y alfareros (Durán y Planella 1989; Sánchez y Massone 1995). La influencia cultural de áreas de más al norte, como hipótesis del surgimiento del fenómeno Aconcagua, es analizada por varios autores (Cornejo 2010; Villaseca y Ayala 1995). Esta característica habría facilitado su incorporación pacífica al Tawantinsuyu y explicaría su capacidad de adoptar y adaptar las instituciones, las creencias, la lengua y el simbolismo incaico (Stehberg et al. 2016).

Entre las evidencias de la presencia Tawantinsuyu en el área destaca un gobernador orejón, Quilicanta; un centro administrativo y ceremonial principal;

1 Área de Antropología, Museo Nacional de Historia Natural, Chile. Ruben.stehberg@mnhn.cl

Recibido: julio 2015. Aceptado: julio 2016.

http://dx.doi.org/10.4067/S0717-73562016005000027. Publicado en línea: 22-agosto-2016. 
presencia del Qhapaq Nan; elevado desarrollo hidroagrícola; cambios en la modalidad de funebria; un adoratorio principal en el cerro El Plomo; sacralización del paisaje; introducción de la lengua quechua y la incorporación aparentemente pacífica y activa de la población local en la nueva administración (Stehberg y Sotomayor 2012).

El pucará de Chena constituye uno de los sitios más representativos, ya que por su amplio dominio visual sobre el valle del Maipo le permite controlar los dos accesos desde el sur al valle del Mapocho protegiendo, de esta manera, el mencionado centro administrativo y ceremonial Tawantinsuyu; y los asentamientos agrícolas emplazados en ambos valles (Stehberg 1976) (Figura 1). El sitio también es destacado como un lugar de observaciones astronómicas y huacas (Boccas 2004; Bustamante 1996; Moyano 2010; Stehberg 2006).

Los actuales proyectos de investigación de la temática incaica han contemplado la reexcavación del sitio con el fin de incrementar los conocimientos acerca de este importante lugar. El proyecto FONDECYT 1140803/2014 liderado por Daniel Pavlovic ${ }^{1}$ se centra en el papel jugado por la población local durante la ocupación Tawantinsuyu, mientras que el proyecto FONDECYT 1140043/2014 dirigido por Rubén Stehberg ${ }^{2}$ se orienta hacia la comprensión de las actividades que se realizaron en la cumbre del cerro, al interior de la plaza intramuros. El presente artículo da cuenta de los resultados obtenidos en este último proyecto.

En el extremo SE de la plaza intramuros de Chena existe una acumulación de piedras y tierra de aspecto muy irregular que, pese a su especial localización dentro del sitio, no había sido objeto de un estudio arqueológico exhaustivo. La única intervención conocida es realizada, en diciembre de 1957, por Hans Niemeyer y Roberto Bobadilla, quienes encuentran un promontorio de piedra y tierra de $8 \mathrm{~m}$ de diámetro y $0,80 \mathrm{~m}$ de altura, con vestigios de un muro de contención en la parte sur y presencia de una delgada capa de cenizas bajo un emplantillado de grandes piedras y un fragmento de cerámica pintada roja (Stehberg 1976:3-10, 1995:165). La función del montículo no es definida y los resultados de la excavación permanecieron inéditos. Los estudios desarrollados por Stehberg, durante 1975 y 1977, tampoco incluyen su excavación.

A partir de 1995, la hipótesis que la función del montículo de Chena debe corresponder a un ushnu comienza a ser mencionada en los artículos relacionados con el sitio (Boccas 2004; Bustamante 1996; Llagostera 2013; Moyano 2010; Stehberg 1995; Stehberg y Sotomayor 2012).

Con el objetivo de someter a contrastación esta hipótesis y, de precisar su funcionalidad, adscripción cultural y cronología, durante el 2014 se realizan excavaciones sistemáticas en el montículo con el fin de determinar su funcionalidad, adscripción cultural y cronología ${ }^{3}$. Este artículo da cuenta de los análisis realizados y los resultados obtenidos. Se inicia con la revisión de la literatura especializada para conocer los principales elementos arquitectónicos que se encuentran al interior de las plazas incaicas, en especial las plataformas-ushnus, con la intención de verificar si estos atributos están presentes en Chena.

\section{Antecedentes de $\boldsymbol{U}$ shnu, Plataformas y Plataformas-Ushnu}

La revisión bibliográfica tiene por objetivo identificar los principales rasgos arquitectónicos que se encuentran en las plazas de los sitios incaicos, definiendo sus atributos, su significado y función, con el fin de comprender, caracterizar y comparar los restos culturales encontrados en Chena. Existen numerosas referencias documentales a la presencia de elementos arquitectónicos incaicos dispuestos tanto al interior de las plazas del Cusco como en otros lugares importantes a lo largo del Tawantinsuyu:

...el Inca Yupanqui ....hizo poner en medio de la plaza del Cuzco donde ahora es el royo una piedra de la hechura de un pan de azúcar puntiaguda para arriba y enforrada... la piedra se puso en medio de la plaza del Cuzco hízose en ella un gran hoyo primero (Betanzos (2010:94-95 [1551, Cap. XI]). ...en la gran plaza de la ciudad del Cuzco, estua (estaba) la piedra de la guerra que era grande, de la forma y hechura de un pan de azúcar, bien engastada y llena de oro... Cieza de León (1962[1553: folio 30v]). ...en medio de la plaza tenía un pilar de piedra muy labrada, de un estado de alto $(1,6718 \mathrm{~m}) \ldots$ que le nombraron Osno... (Anónimo 1906:151,158 [ca. 1565]).

en el usño que como dicho es a manera de pila de piedra enforrada en oro la qual tenia vn abujero debajo de la tierra hasta las cassas del sol y el trueno y Hacedor... (de Molina (2008 [1574-5]). 


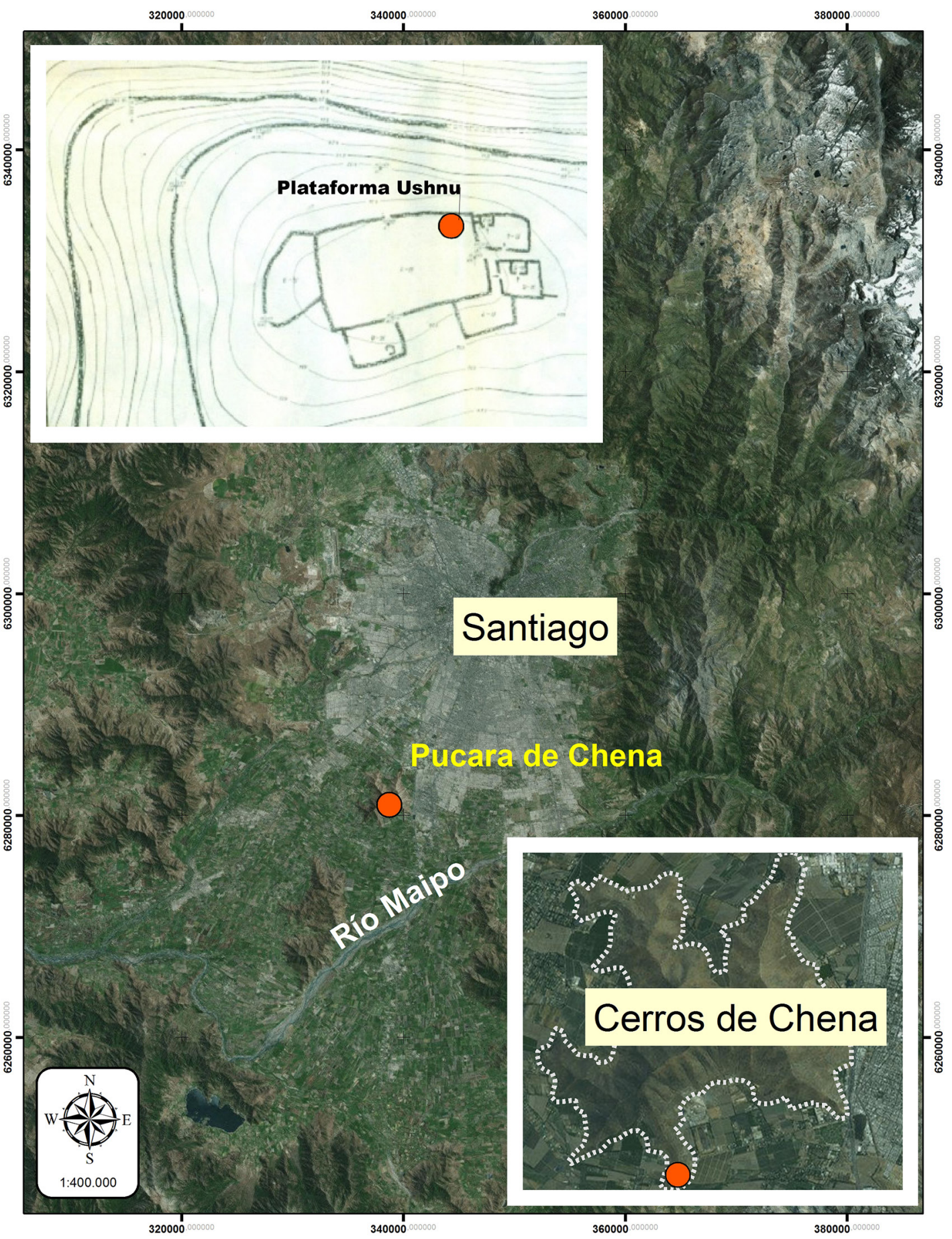

Figura 1. Localización del pucará de Chena, entre el río Maipo y el río Mapocho (Santiago). Location of the Pucara of Chena, between Maipo river and the Mapocho river (Santiago). 
Estos cronistas enfatizan en la existencia de una piedra de forma de pan de azúcar, trabajada y cubierta en oro, y la presencia de un agujero. No mencionan la existencia de plataforma $\mathrm{o}$ arquitectura asociada, aunque ello no significa que no haya existido. Cabe destacar que las primeras referencias no mencionan estos elementos con el nombre de ushnu, denominación que se impondrá a partir de la segunda mitad del siglo XVI. Basado en estos y otros antecedentes, Zuidema (2014:5-25) concluye que la esencia del ushnu es servir como receptáculo para recibir líquidos u ofrendas mediante el agua y conducirlos al mundo subterráneo. Otros elementos arquitectónicos asociados tienen su propia función y denominación, lo que ha llevado a confundir el significado original del ushnu.

Desde el punto de vista arqueológico, estos elementos son difíciles de encontrar. Una piedra sagrada, un agujero o un drenaje son muy posibles que hayan sido vandalizados o eliminados por los extirpadores de idolatría (Hyslop 1990:72). Sin embargo, hay excepciones. En el mismo valle donde se encuentra el pucará de Chena se conserva un agujero central en las ruinas de Chada. Se trata de un complejo arquitectónico aledaño al Qhapaq Ñan, localizado a $50 \mathrm{~km}$ al sur de Santiago. Allí, el orificio está rodeado de dos cimientos perimetrales concéntricos con un diseño muy complejo (Stehberg et al. 1997). Dicho foso es interpretado como el ushnu del lugar y es similar a uno existente en la fortaleza de Sacsayhuamán, en Cusco (comunicación personal Dr. Farrington, 1998). Sin embargo, es en los centros administrativos y otros lugares de importancia política o religiosa distribuidos en las provincias donde se reconoce con mayor facilidad la presencia de estructuras de forma piramidal con una o más plataformas, escalinatas, rampas y conductos para agua: son las llamadas plataformas ushnus. Por ejemplo, cuando Huayna Capac manda a construir sus palacios en Tomebamba (Ecuador):

Hizo el edificio en la plaza para el uso del usmo que llaman los indios Chuqui pillaca, para sacrificar la chicha al sol cuando bebían con él (Murúa 1986 [1611]:113).

Un buen ejemplo de plataforma-ushnu en el valle del Mapocho se encuentra en el adoratorio incaico del cerro El Plomo, con estructura piramidal y agujero en su interior (Mostny 1957). Respecto de la función de estas estructuras existe consenso entre los especialistas en que son utilizadas por los Incas y sus gobernadores para comunicarse con sus súbditos, sus divinidades y sus ancestros y donde realizan las principales festividades, observaciones solares y lunares, y donde comienza el calendario agrícola. Sentado sobre la plataforma, la autoridad establece una conexión vertical simbólica entre las deidades celestiales, las divinidades cordilleranas y los ancestros. Una función esencial es alimentar a los ancestros del $u k u$ pacha, principalmente a través del agujero tallado en la roca (Meddens et al. 2010:173-176, 191).

La plataforma ushnu representa una forma material de wak'a y su rol se vincula a la necesidad del Estado Inka de proyectar a través de su territorio, de manera rápidamente reconocible para los grupos sujetos, el dominio del Cusco sobre las deidades regionales (Meddens 2015:239) mostrando a la gente no inca su lugar dentro de la cosmología estatal imperante. Las plataformas localizadas dentro de los asentamientos incaicos y en localidades prominentes del paisaje son usadas para ejercer control sobre poblaciones conquistadas recientemente y sus territorios (Branch et al. 2014). En territorios conquistados one finds ushnu platforms, uniting the idea of Inka nobility to the breat plazas, which are in turn associated with common and non-Inka peoples (Hyslop (1990:70 y sigs.), uniendo políticamente el Cusco con los centros provinciales. Se trata de

una estructura arquitectónica simbólica del poder que se halla solo en instalaciones políticamente jerarquizadas dentro del planeamiento urbano inka (Raffino 2004:74).

\section{Asimismo, se la considera}

una especie de podio destinado al inka y a los altos dignatarios del Tawantinsuyu, desde el cual dirigían las ceremonias de carácter político-religioso, y hablaban a sus súbditos. Los objetos de este tipo eran uno de los símbolos de la ideología imperial, y aparecían en todas las provincias del estado (Presbítero 2000-2001:187).

De acuerdo con la información etnohistórica, la construcción de una roca erguida en una plataforma en la plaza, proyectándose hacia el cielo, representa una montaña, un punto de entrada al mundo superior, hanan pacha (plataforma, escalera, banqueta), 
mientras que su utqu o qocha asociado (pozo, agujero, canal, dren, tumba o qocha cueva) es una entrada ontológica al mundo subterráneo, ukhu pacha. Como consecuencia, el complejo ushnu constituye un punto pivotal en la comunicación terrenal con el mundo superior e inferior. Su función es articular la legitimación del rey inca y ser el foco de la principal ceremonia estatal. Puede ser considerado como el monumento prototipo de la identidad inca debido a que encarna sus creencias cosmológicas más profundas (Farrington 2013, 2014).

El ushnu sirve como axis mundi, para ceremonias religiosas importantes relacionadas con solsticios, lunisticios y culto a las huacas de la montaña; para observaciones sistemáticas del cielo, reconocimientos de rasgos significativos del paisaje (wak'as), y fuentes de agua y áreas agrícolas. Asimismo, constituye un punto de observación que establece relaciones a través de líneas de mira (posibles ceques) con ciertos elementos del paisaje o del horizonte que incluye elementos fíjos (cerros, edificios, marcadores culturales) y elementos móviles como el sol, la luna, las estrellas y ciertas áreas de la Vía Láctea (Moyano 2014:194).

Con relación a las características formales que presentan las plataformas-ushnus a lo largo de las provincias incaicas existe bastante información. Usualmente se las clasifica en tres tipos: (1) las que forman parte de sitios administrativos inca localizados en grandes espacios comunales o plazas; (2) las que se encuentran en los principales sitios de peregrinaje y; (3) las que conforman unidades aisladas frecuentemente localizadas en cumbres montañosas elevadas (Meddens 2014:57, 2015:241). La instalación de Chena, objeto de este artículo, podría corresponder al primer tipo, mientras que la plataforma ceremonial del cerro El Plomo (Mostny 1957) incumbiría al tercero.

"Es precisamente dentro de las grandes plazas de los asentamientos Tahuantinsuyo donde encontramos localizados los ushnus, generalmente uno por asentamiento y uno por plaza" (Monteverde 2010:46), localizándose al centro o en uno de sus bordes, directamente relacionados con caminos internos que sirven para desplazarse dentro del asentamiento y, usualmente, cercanas al Qhapaq Ñan.

Los asentamientos Tahuantinsuyu fuera del Cuzco presentan ushnus a modo de una o más plataformas, de diversos tamaños y planta rectangular, cuadrangular o trapezoidal y que pueden presentar vanos, escalinatas y/o rampas de acceso, siempre abiertas hacia la plaza misma (Monteverde 2010).

En el planeamiento Inca Provincial no está claro hasta qué punto las plataformas ushnu incorporaron piedras, pozos y drenaje, ya que en algunos casos estas se encuentran fuera de la plataforma (Hyslop 1990:100).

Respecto de las técnicas constructivas existe una gran flexibilidad en lo que se refiere a las dimensiones de la planta, altura y técnicas utilizadas. De estas últimas, la mayoría presenta aparejo de factura rústica o sencilla, en piedra o adobe (Monteverde 2010:53, 56). En cuanto a las escalinatas, casi siempre es una sola en la parte central de la plataforma ushnu que enfrenta la plaza $\mathrm{y}$, en caso que el estrado sea pequeño y su altura no sobrepase el metro de altura, no se le construye ninguna. Además, puede contar con una rampa en su lado posterior que sirve para el descenso de las personas. Las rampas y escalinatas, cuando las hay, son amplias, permitiendo el tránsito de más de una persona a la vez. Con relación a los pozos, la mayoría se emplaza en la plataforma superior y central del ushnu, son de poca profundidad (menos de $1 \mathrm{~m}$ ), de planta rectangular y, en muchos casos, se halla gran cantidad de cantos rodados en su interior y en su piso. Usualmente hay canales dentro y fuera del иshnu (Monteverde 2010:58, 59, 72). Por otra parte, de existir materiales constructivos traídos de lugares alejados tienen relación con la idea de vincular la plataforma con un paisaje más amplio, satisfacer a los ancestros y deidades y asegurar el uso del suelo para la agricultura, para el asentamiento inca y para el control del territorio (Branch et al. 2014:116).

Respecto de los vestigios que pueden estar directamente asociados a los ushnus y a las actividades que se realizan en sus contornos inmediatos recopilados a partir de los restos arqueológicos recuperados en excavaciones en sitios como la plaza del Cusco, Huánuco Pampa y Shinkal, destacan: alineamientos de piedras de factura inca asociados a figurillas de camélidos de Spondylus, oro y plata; restos cerámicos de distintas partes del Tawantinsuyu y del Cusco mismo; consumo de chicha (aqha); quema de plantas alimenticias, llamas y tejidos; ofrendas humanas y de llamas, cenizas, carbón; objetos rituales como pectoral de plata, conchas y cuentas de Spondylus princeps; cuchillos líticos; 
cuentas de turquesa; tupus de cobre, plata y oro; piedras qonopa; evidencia de trabajo en metal y muchos otros objetos (Farrington 2013, 2014; Farrington y Raffino 1996). Con todo:

la principal ofrenda y la mejor... es la chicha por ella, y con ella comienzan todas las fiestas de las huacas... Y assi tienen para este efecto muchos vasos, y vasijas de diferentes formas, y materias y...que dan a beber a las huacas... (Arriaga 1920:42 [1621, Cap. IV]

confirmando la existencia de todo un conjunto de utensilios relacionado con la práctica de las libaciones o de ofrendas líquidas que se vierten en los pozos y rocas de los ushnus. De acuerdo con fuentes históricas de los Andes Centrales, la principal festividad que se efectúa en estas plataformas ceremoniales es la situa, ceremonia de purificación y de alianzas político-religiosas, donde los problemas políticos, económicos, administrativos y/o de poder en el Tawantinsuyu son tratados y analizados. Reunidos en torno al ushnu, se festeja mientras se realizan pronósticos y vaticinios, para el éxito de la siembra y otros asuntos estatales, soplando las entrañas de camélidos sacrificados en la plaza (Monteverde 2011: 250-251).

\section{Metodología de Campo}

Los trabajos en terreno fueron realizados en noviembre y diciembre de 2014 y consistieron en la excavación de una red de cuadrículas de $1 \mathrm{~m} \mathrm{x}$ $1 \mathrm{~m}$ que cubrió casi la totalidad de los montículos de tierra y piedra existentes de la plaza intramuros de Chena y que, a la sazón, se encontraban cubiertas de vegetación. Se rebajó por niveles estratigráficos naturales y artificiales, cambiando de nivel cada 5 $\mathrm{cm}$. Se excavó hasta llegar a los bloques rocosos que se encontraban entre los 0 y $20 \mathrm{~cm}$ de profundidad, retirando los sedimentos y dejando la estructura visible (Figura 2). Los bloques rocosos y la tierra que los unía quedaron en su lugar original y no se profundizó la excavación para evitar el deterioro del rasgo (Figura 3).

El punto cero de referencia consistió en una estaca de fierro que se enterró en el extremo SW del montículo y desde el cual se trazaron las cuadrículas hasta cubrir todo el montículo. Se orientaron respecto del norte magnético y se numeraron correlativamente (Figura 4).

A $50 \mathrm{~cm}$ al sur del punto cero se instaló, entre el 19.12.2014 y el 26.02.2015, un dosímetro TL requerido por el Laboratorio de Termoluminiscencia de la Universidad Católica de Chile, para datar dos fragmentos de cerámica. Los sedimentos fueron

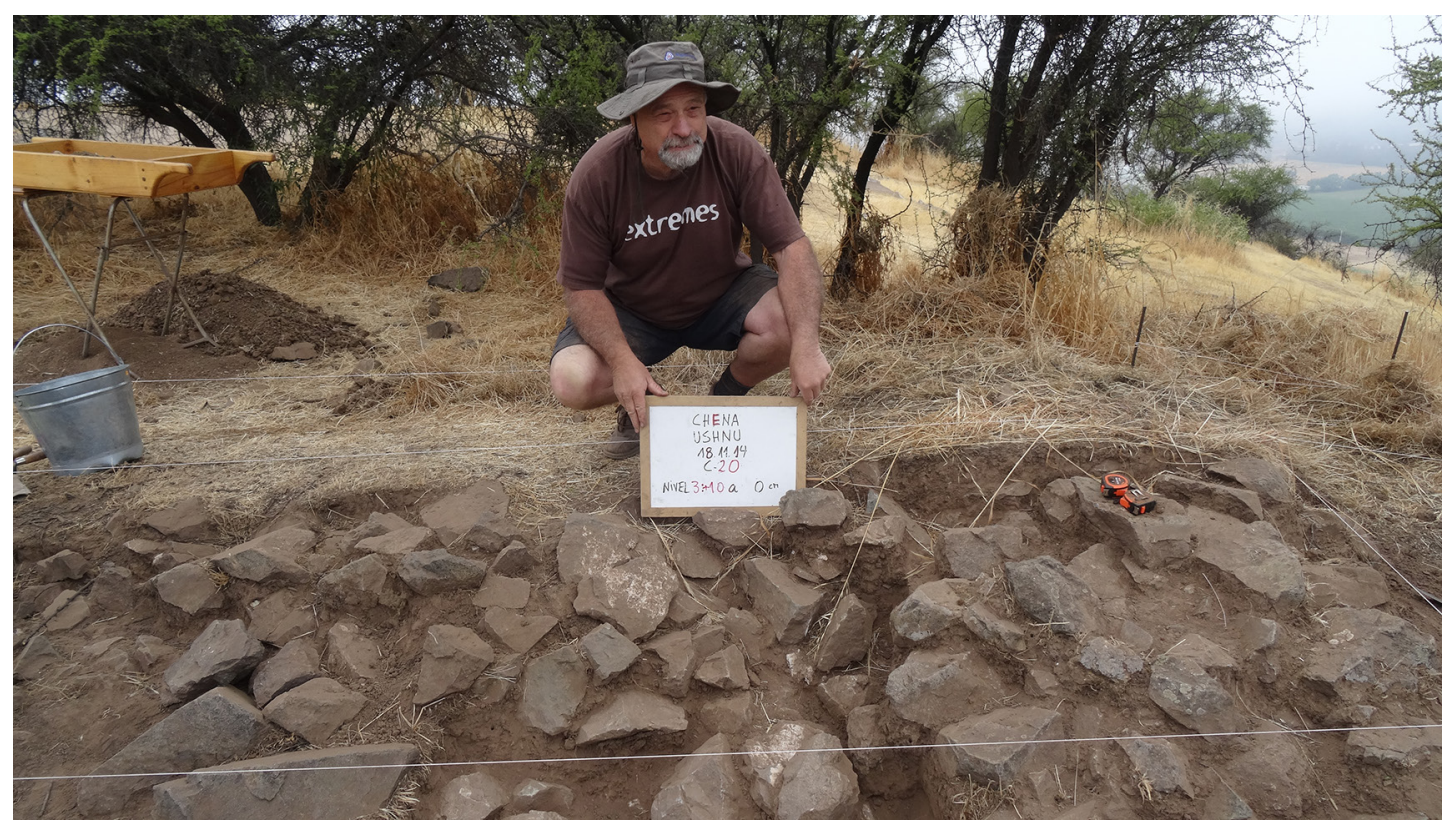

Figura 2. El autor mostrando la masa compacta de bloques y tierra que conforman la superficie de la plataforma. The author showing the compact mass of earth and blocks that make up the internal structure of the platform. 


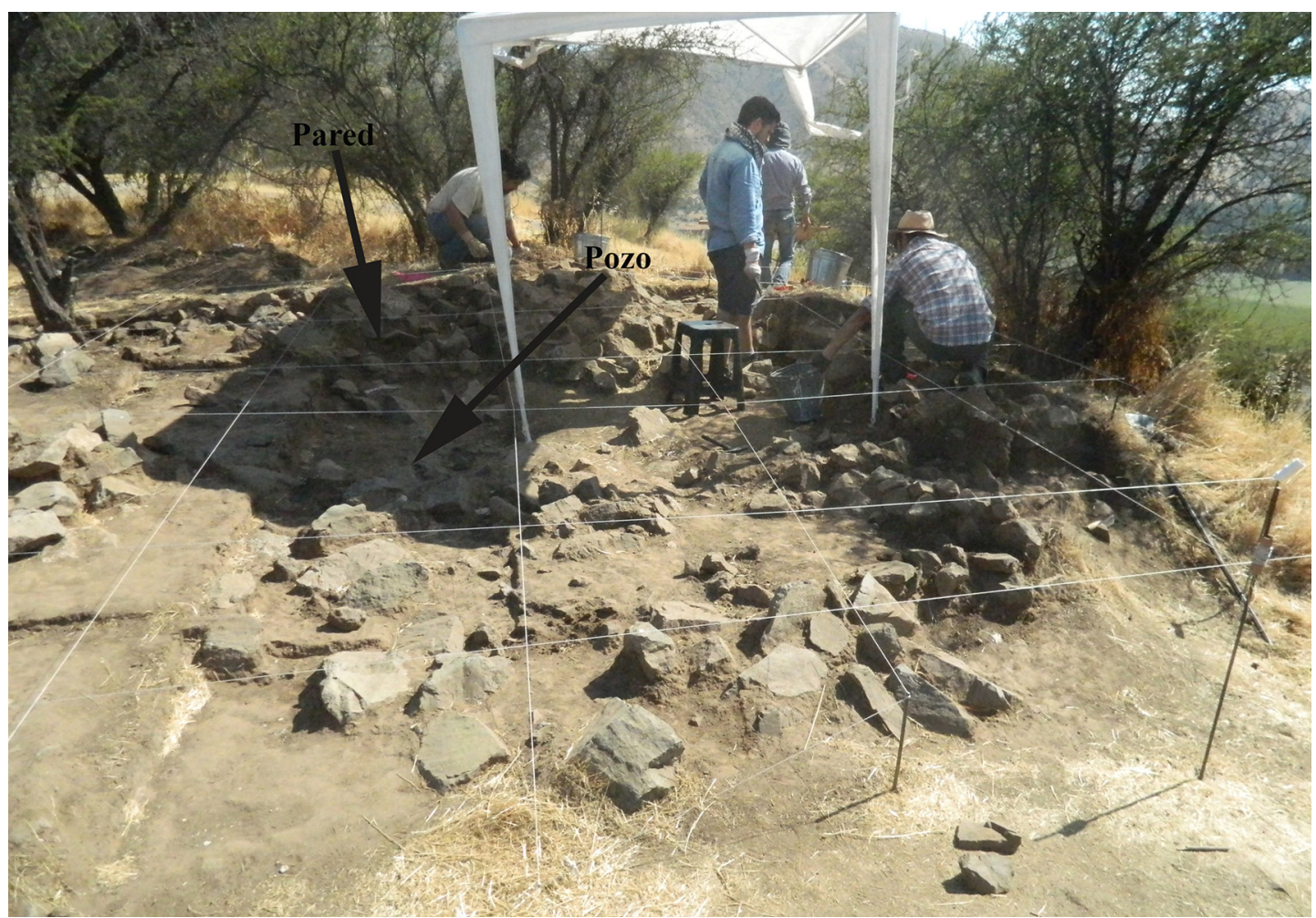

Figura 3. Excavación por cuadrículas de 1m x 1m orientadas al norte.

Excavation of $1 \mathrm{~m} \times 1 \mathrm{~m}$ squares oriented north.

tamizados en malla de $0,4 \mathrm{~mm}$ y los restos muebles fueron embolsados y etiquetados por cuadrícula y nivel, embalados y enviados al Laboratorio de Arqueología del Museo Nacional de Historia Natural para su correspondiente análisis. Los detalles fueron anotados en un cuaderno de campo y se documentó fotográficamente cada nivel excavado. Se tomaron fotos aéreas con un Dron ${ }^{4}$. Finalmente, la excavación fue tapada, en febrero 2015, con malla rashel, geotextil y los mismos sedimentos extraídos de su interior. Los análisis de laboratorio siguieron los procedimientos actualmente en uso para estos materiales los cuales, por su extensión, no se detallan 5 .

\section{Resultados}

\section{Descripción de los restos arquitectónicos}

La estructura interna de la plataforma corresponde a una aglomeración de bloques rocosos canteados de tamaño mediano unidos con tierra formando una masa compacta (Figura 2). La roca, en su mayoría, procede de la cantera que se encuentra en la ladera sur del cerro. Esta construcción ha resistido mal los sismos, las lluvias torrenciales y la vegetación arbustiva (espinos), que la han afectado, constituyéndose en las principales causas de su deterioro (Figura 5). El daño por la acción antrópica es menor y podría reducirse a la depresión de $2,5 \mathrm{~m}$ x $0,5 \mathrm{~m}$, de dirección N-S que existe en el sector $\mathrm{NE}$ de la plataforma (sector intermedio entre C-35 y $40 ; \mathrm{G}$ y 45 y, H y 42). Esta fosa se efectúa antes de 1975, fecha en que nos consta que la alteración ya estaba presente. Las excavaciones practicadas no aportan materiales anteriores a 1978, fecha de apertura del parque al público, lo cual refuerza la idea que la mayor destrucción fue ocasionada por eventos naturales.

La mitad norte de la estructura está mejor conservada, mide $4 \mathrm{~m}$ x $3 \mathrm{~m}$ y $0,60 \mathrm{~m}$ de altura máxima respecto del punto cero, con bloques rocosos cuya dimensión oscila entre $0,15 \mathrm{~m}$ x $0,30 \mathrm{~cm}$ de largo. Una elevación similar, de 4,5 m de largo y $0,70 \mathrm{~m}$ de ancho, aparece poco más al oriente, separada por la depresión recién mencionada. Luego, 


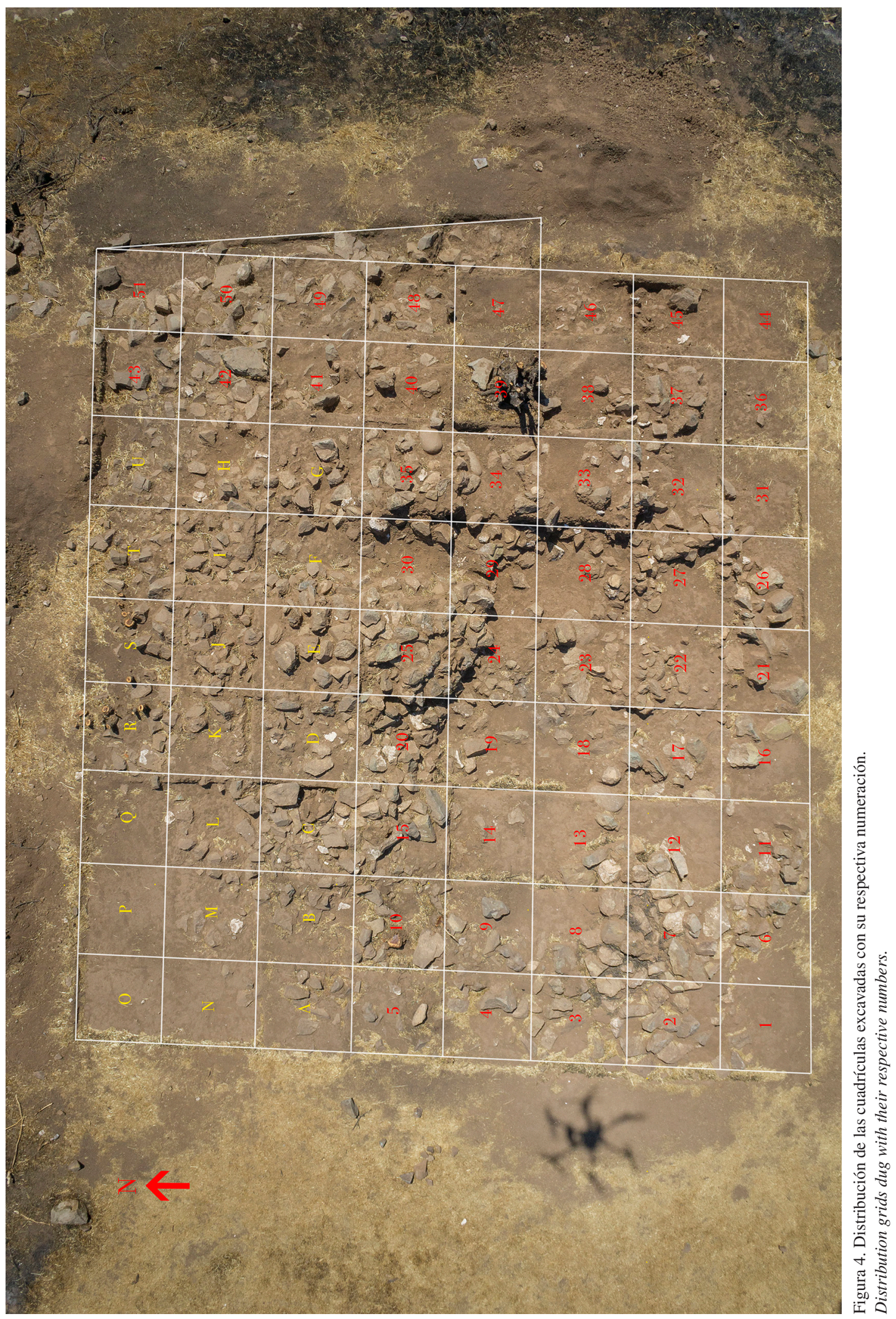




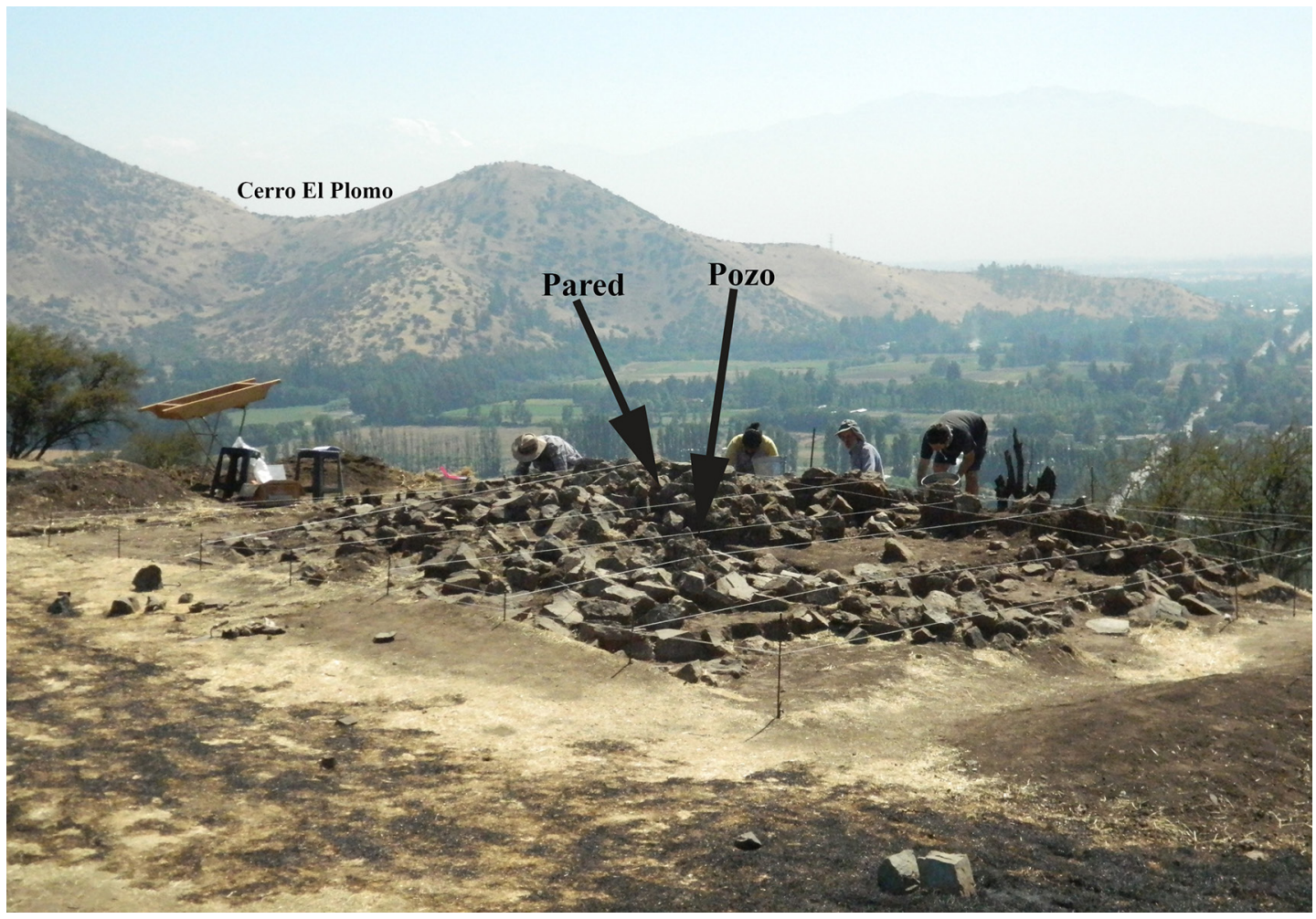

Figura 5. La estructura luego del despeje de los sedimentos que la cubrían. Se observa el grado de deterioro de la estructura, principalmente en su mitad sur. La flecha indica el lugar del agujero central (ushnu).

The structure after the clearance of the sediments that covered it. The degree of deterioration of the structure is observed mainly in the southern half. The arrow shows the place of the central hole (ushnu).

la estructura desciende abruptamente hacia el oriente hasta empalmar con el muro perimetral E de la plaza, formando un rampa o talud escalonado de piedra de 7,0 $\mathrm{m}$ de largo y $2,5 \mathrm{~m}$ de ancho (Figura 6). El otro sector elevado se localiza en el extremo SW, mide $2 \mathrm{~m}$ x $2 \mathrm{~m}$, aproximadamente, y alcanza una altura de $0,37 \mathrm{~m}$ respecto del nivel de referencia.

El vaciamiento más amplio tiene su inicio en una pared de piedra y tierra de cuatro hiladas y $1,4 \mathrm{~m}$ de extensión, localizada aproximadamente en el centro de la estructura (C-20 y C-24). Esta pared es parcialmente visible en las Figuras 3, 5 y 7, siendo el único muro encontrado en la plataforma. El piso está formado por bloques canteados homogéneos de entre $0,30 \mathrm{~m}$ y $0,45 \mathrm{~m}$ de largo, dispuestos paralelos y perpendiculares a la pared (Figura 7). La pared y el piso constituyen los dos rasgos que sobreviven del agujero central (ushnu).

El vaciamiento se continúa en forma irregular hacia el SW, cubriendo una superficie de $3 \mathrm{~m} \mathrm{x}$ $3,5 \mathrm{~m}$. La base presenta bloques más pequeños de $0,1 \mathrm{~m}$ y $0,20 \mathrm{~m}$ de longitud, quedando sectores donde los cimientos y la estructura han desaparecido completamente, situación que se da en los extremos NW, SW y SE. Es claro que el mayor deterioro comienza a partir de este agujero central, con vaciamiento de material hacia el SE, siguiendo la pendiente del lugar. No se reconocen restos de muros ni escalinatas de acceso. Existen seis bolones grandes de río traídos al lugar y cuya descripción se proporciona más adelante. Se distribuyen preferentemente en el sector centro sur de la instalación y en la mitad norte del talud o rampa posterior.

La Tabla 1 muestra las alturas máximas y profundidades mínimas encontradas al interior de la estructura excavada, medidas a partir del punto de referencia cero.

\section{Sedimentología}

Debido a información arqueológica que señala que algunas plataformas estaban rellenas con sedimento arcilloso traído de un río cercano, además 

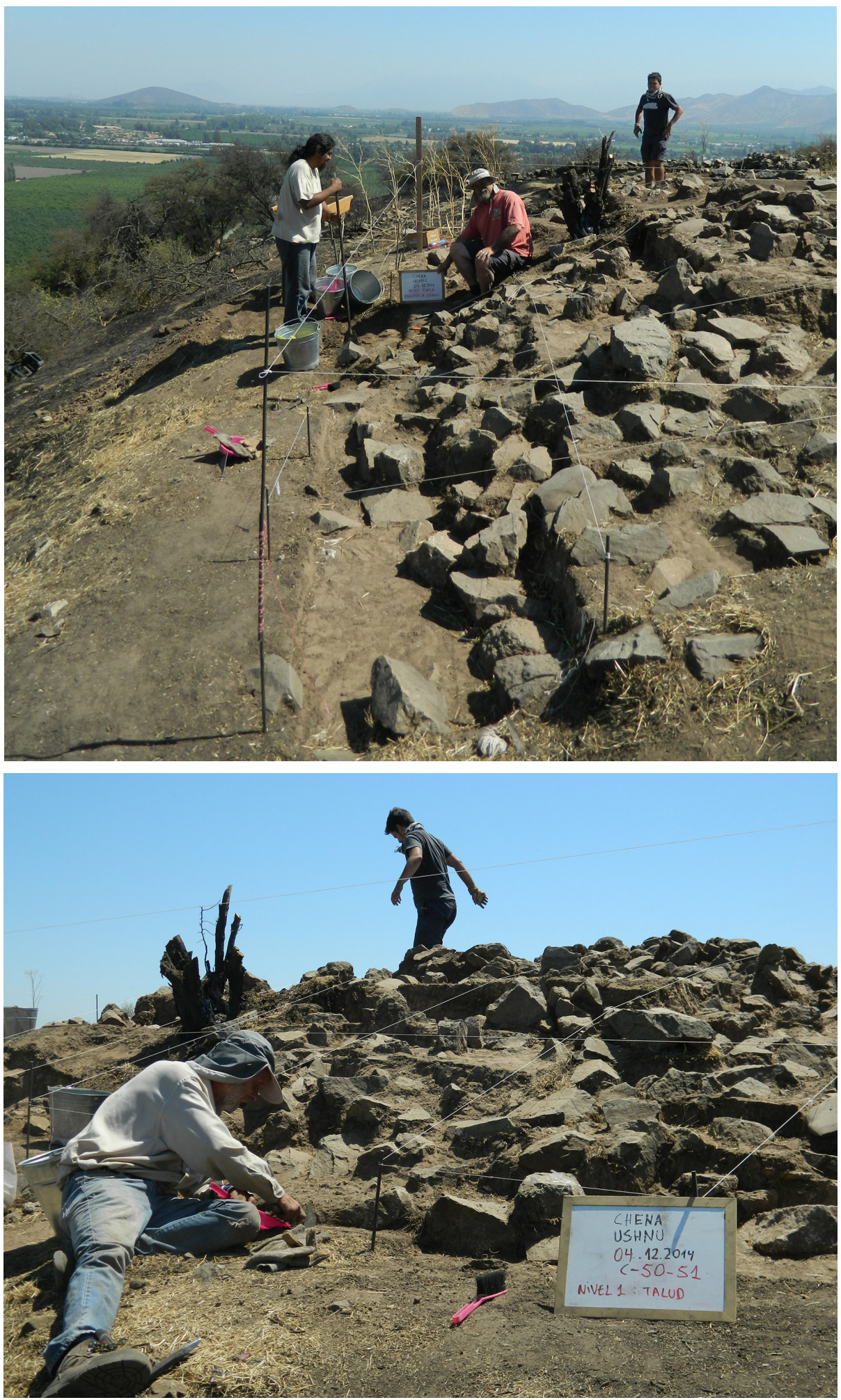

Figura 6. Vistas de la rampa posterior que llega al muro perimetral oriente de la plaza. Nótese el declive abrupto de la rampa.

Views of the rear ramp that reaches the perimeter fence east of the square. Note the sharp decline of the ramp. 
Tabla 1. Alturas máximas y profundidades mínimas encontradas en la estructura interna de la plataforma. Maximum height and minimum depths of the internal platform structure.

\begin{tabular}{cccc}
\hline Cuadrícula & Elevación $(\mathrm{cm})$ & Cuadrícula & Profundidad $(\mathrm{cm})$ \\
\hline $\mathrm{E}$ & 60 & 48 & -84 \\
15 & 54 & 49 & -82 \\
8 & 54 & 50 & -80 \\
25 & 51 & 51 & -83 \\
35 & 43,7 & 47 & -65 \\
$\mathrm{G}$ & 43 & 45 & -60 \\
32 & 38,5 & 44 & -60 \\
33 & 38,5 & 36 & -48 \\
& & 31 & -32 \\
\hline
\end{tabular}

de rocas o barro sellado (Monteverde 2010:53, 56), se estimó conveniente conocer la sedimentología de la plataforma de Chena. Las dos muestras analizadas correspondieron a sedimento fino de tipo limo y limo fino, compuesto de $51 \%$ de fragmentos clásticos, $36 \%$ de cuarzo y $13 \%$ de feldespato, con presencia de restos orgánicos tipo raíces y carbón (Martínez y Salazar 2015:4). Lo más probable es que el origen del material fuera local, quizás parte de la remoción que se efectuó durante los trabajos de aplanamiento de la cumbre del cerro.

\section{Restos arqueológicos}

El Anexo 1 muestra la distribución de los materiales excavados, donde los primeros siete ítems (cerámica, lítico, piedras rodadas, bolones, toba, malacológico, óseo animal) corresponden a restos prehispánicos, la mayoría relacionados con actividades ceremoniales (ofrendas). Los tres siguientes (metal, vidrio, plástico) conciernen a restos posteriores a $1978 \mathrm{y}$, el último ítem (otros), atañen a elementos que no pertenecen a las categorías anteriores, como cuesco, baldosa y azufre.

\section{Cerámica}

La Tabla 2 describe el material cerámico encontrado en las cuadrículas que presentan el mayor número de fragmentos.

La distribución de los fragmentos cerámicos es interesante. Las cuadrículas 18 y 33 se encuentran al sur del pozo central, en el área de vaciamiento por gravedad de la estructura interna de la plataforma, lo que supone que estos materiales se desplazaron de su lugar original como parte del proceso de formación del sitio. De igual manera, los fragmentos cerámicos de las cuadrículas 45 y 51 se encuentran en la base de la rampa, lo que supone que cayeron desde puntos más elevados, supuestamente la plataforma superior.

Respecto del material cerámico encontrado, cabe mencionar que la totalidad es asignable a la ocupación Tawantinsuyu. La mayoría de los fragmentos corresponden a piezas abiertas, tipo plato o escudilla. Aunque en la plataforma solo se encuentran tres fragmentos atribuibles a aríbalos o aribaloides, igualmente es importante destacar que estas formas están presentes en los recintos que rodean la plaza intramuros y, en forma bastante abundante, en los dos cementerios de San Agustín de Tango pertenecientes al período Tawantinsuyu asociados al sitio (Stehberg 1976). Debido al pequeño tamaño de los fragmentos, solo se reconoce una unidad mínima de diseño correspondiente al patrón Diaguita clásico Doble Zigzag A, mientras que el resto corresponde a fragmentos de diseños y formas cerámicas características del período Tawantinsuyu y del tipo Aconcagua Anaranjado variedad monocroma. Cabe destacar la presencia de esta última cerámica, representativa de la población local. Asimismo, se resalta la presencia de una cabeza de ánade propia de los platos ornitomorfos incaicos (Figuras 8 y 9).

Se efectúa análisis de pasta a 76 fragmentos identificándose seis familias de pasta. La Tabla 3 describe las tres primeras familias, ya que concentran la mayor parte de la muestra $(84,2 \%)$.

Se distinguen 17 patrones de pasta, donde se mezclan distintas proporciones de áridos de origen volcánico y granítico, pudiéndose inferir que las vasijas fueron elaboradas "a partir de distintas fuentes de materias primas, aunque estas comparten características comunes de selección y distribución 


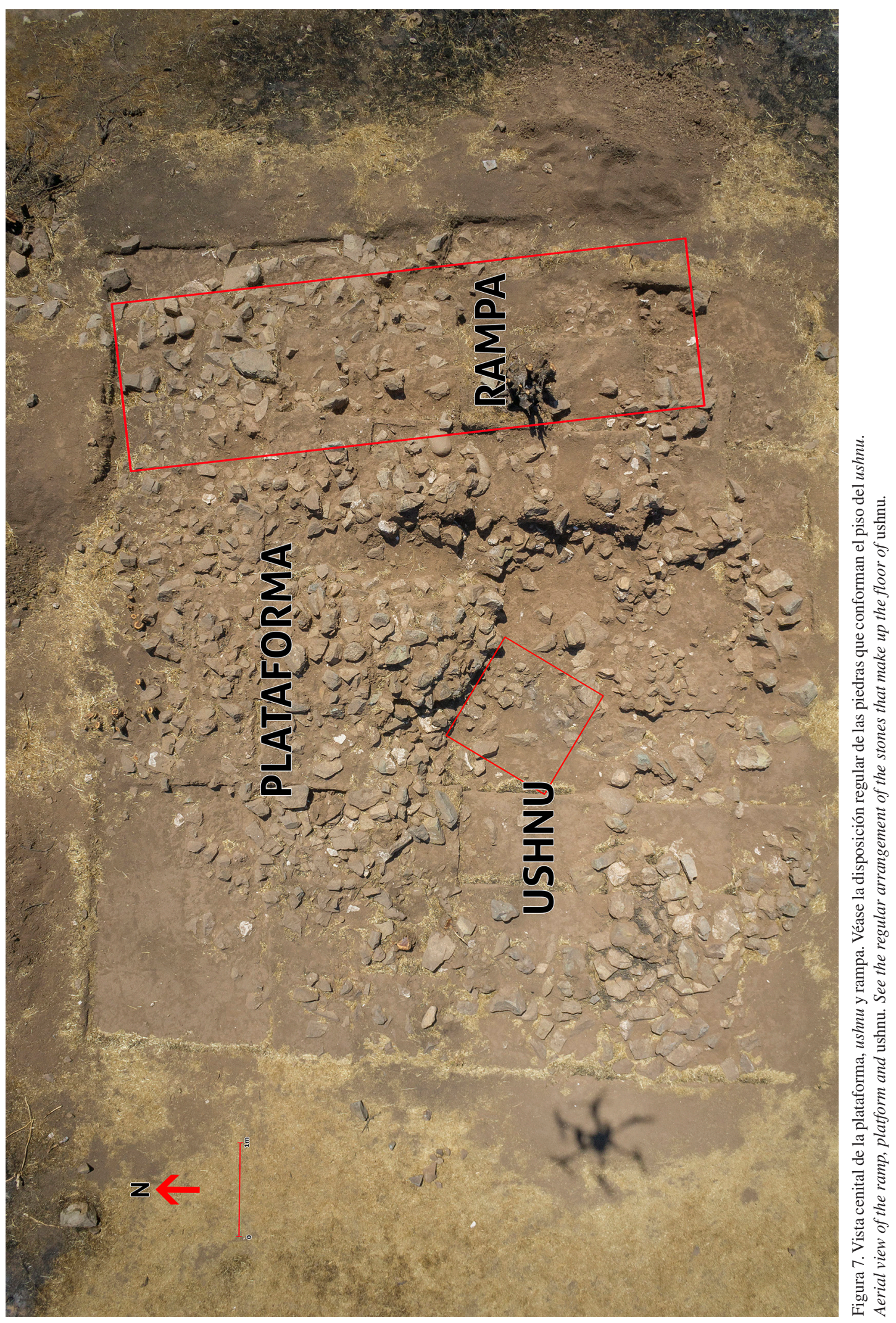


Tabla 2. Descripción del material cerámico por cuadrícula excavada.

Description of pottery sherds by excavated unit.

\begin{tabular}{|c|c|c|c|}
\hline Cuad. & $\begin{array}{l}\text { Prof. } \\
(\mathrm{cm})\end{array}$ & $\begin{array}{l}\text { Cantidad } \\
\text { fragmentos }\end{array}$ & Descripción \\
\hline 33 & 20 & 13 & $\begin{array}{l}\text { Seis corresponden a un mismo plato, tres de ellos son bordes con labio redondeado y } \\
\text { engrosado. Tienen engobe rojo al exterior y decoración interior negra sobre blanco, } \\
\text { consistente en una línea gruesa paralela al borde y en el labio, 5,4 a } 6,5 \mathrm{~mm} \text { grosor } \\
\text { (Figura 8). } \\
\text { Uno con engobe rojo al interior y café alisado al exterior, } 6,1 \mathrm{~mm} \text { grosor. } \\
\text { Seis poseen superficie café alisado en ambas caras, } 5,8 \text { a } 8,0 \mathrm{~mm} \text { grosor. }\end{array}$ \\
\hline 18 & $30-40$ & 10 & $\begin{array}{l}\text { Ocho corresponden a una misma vasija, con engobe rojo al exterior, alisado pardo claro } \\
\text { al interior y } 4,8 \mathrm{~mm} \text { grosor. } \\
\text { Uno pardo alisado ambas caras, } 7,3 \mathrm{~mm} \text {. } \\
\text { Uno rojo engobado exterior, café alisado interior. }\end{array}$ \\
\hline 45 & $0-10$ & 6 & $\begin{array}{l}\text { Uno rojo engobado exterior, café alisado interior, } 6,3 \mathrm{~mm} \\
\text { Uno borde rojo engobado en ambas caras, con la característica protuberancia de los platos } \\
\text { ornitomorfos incaicos y decoración lineal negra paralela al borde interior (Figura 9). } \\
\text { Dos gris alisado ambas caras, } 6,1 \mathrm{~mm} \text { grosor. } \\
\text { Uno gris alisado exterior, café alisado interior, } 7,9 \mathrm{~mm} \text { grosor. } \\
\text { Uno muy pequeño, presenta coloración anaranjada de su superficie y pasta, que puede } \\
\text { corresponder al tipo cerámico local Aconcagua Salmón (Figura 9). }\end{array}$ \\
\hline 51 & $65-75$ & 5 & $\begin{array}{l}\text { Un borde evertido, labio simple redondeado, rojo engobado ambas caras, posiblemente } \\
\text { aríbalo, } 5,7 \mathrm{~mm} \text { grosor. } \\
\text { Un engobe rojo ambas caras, } 5,3 \mathrm{~mm} \text { grosor. Posiblemente aríbalo. } \\
\text { Dos muy pequeños, engobe rojo-violáceo exterior, blanco interior, uno de ellos es un } \\
\text { borde de labio aguzado, pintado con línea rojo-violácea en la parte superior del borde } \\
\text { y en el labio, } 6,9 \mathrm{~mm} \text { grosor. } \\
\text { Uno café anaranjado alisado ambas caras, enviado a fechar por TL. }\end{array}$ \\
\hline 20 & $20-30$ & 1 & $\begin{array}{l}\text { Uno posiblemente Aconcagua Negro sobre Naranja, donde se reconocen unas tenues } \\
\text { líneas negras, } 6,8 \mathrm{~mm} \text { grosor. }\end{array}$ \\
\hline 29 & $30-40$ & 1 & $\begin{array}{l}\text { Uno decorado n-r-b exterior con un motivo diaguita clásico (Figura 8), patrón Doble } \\
\text { Zigzag A (González 2013:93, 94), engobe blanco interior, 4,3 mm grosor. }\end{array}$ \\
\hline C-D & $0-10$ & 1 & $\begin{array}{l}\text { Uno muy pequeño con decoración lineal geométrica al interior en negro sobre fondo } \\
\text { blanco (Figura 8). }\end{array}$ \\
\hline 50 & Superficie & 1 & $\begin{array}{l}\text { Corresponde al punto de inflexión entre base y cuerpo de una escudilla, con engobe rojo } \\
\text { al exterior y decoración negro y rojo sobre blanco al interior, con un motivo geométrico } \\
\text { (Figura 8). Mide } 6,4 \mathrm{~mm} \text { de espesor en la base y } 5,0 \mathrm{~mm} \text { de grosor de pared en el cuerpo. }\end{array}$ \\
\hline
\end{tabular}

Tabla 3. Descripción de las familias de pastas cerámicas presentes en la plataforma-ushnu. Description of compositional varieties of pottery found in the ushnu-platform.

\begin{tabular}{ccl}
\hline Familia & $\begin{array}{c}\text { Porcentaje } \\
(\%)\end{array}$ & \\
\hline I & 47,4 & $\begin{array}{l}\text { Inclusiones de color blanco y rosado, de textura rugosa y forma irregular, acompañadas de rocas color } \\
\text { rojo y violáceo de forma más redondeada que las anteriores y otras de distintos tonos blanquecinos } \\
\text { y grisáceos de baja esfericidad. }\end{array}$ \\
& 25,0 & $\begin{array}{l}\text { Inclusiones volcánicas opacas redondeadas color gris y violáceo, de textura lisa y antiplásticos } \\
\text { de color blanco y rosado medianamente opacos, de formas cuadrangulares. En menor medida se } \\
\text { observan inclusiones brillantes y traslúcidas. } \\
\text { II }\end{array}$ \\
III & 11,8 & $\begin{array}{l}\text { Presenta inclusiones similares a la Familia I, de color blanco y rosado, textura rugosa y forma } \\
\text { irregular, junto a rocas color rojo y violáceo de forma más redondeada y escasas inclusiones } \\
\text { redondeadas grisáceas de origen volcánico. }\end{array}$ \\
\hline
\end{tabular}



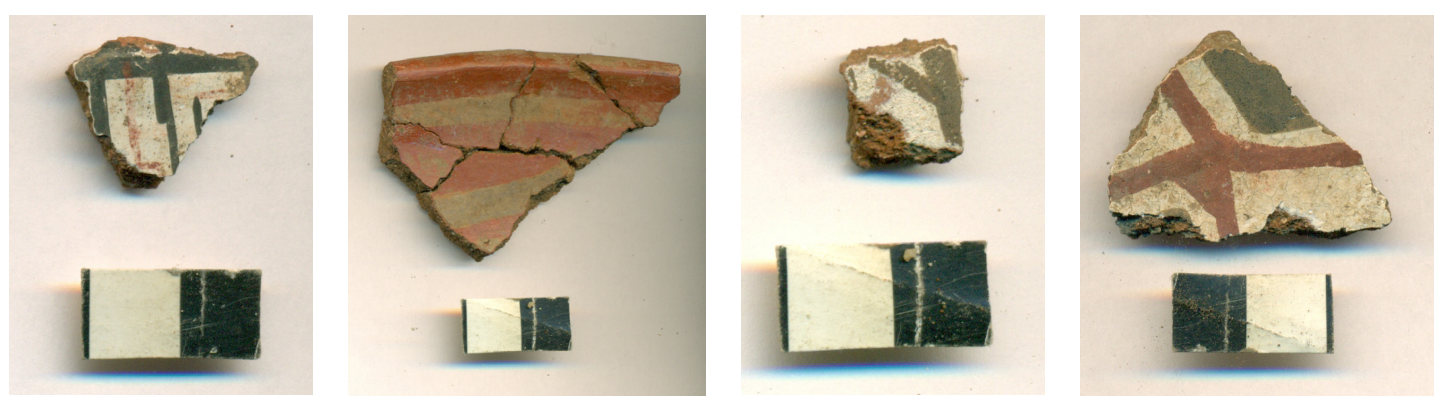

Figura 8. Fragmentos cerámicos decorados de la Cuadrícula 50, nivel 1 (izq.); Cuadrícula 33, nivel 1 (centro), Cuadrícula 29, nivel 3 (derecha); Cuadrícula D, nivel 1 (extremo derecho).

Ceramic fragments decorated Grid 50, level 1 (left); Grid 33, level 1 (center), Grid 29, level 3 (right); Grid D, level 1 (last one the right side).

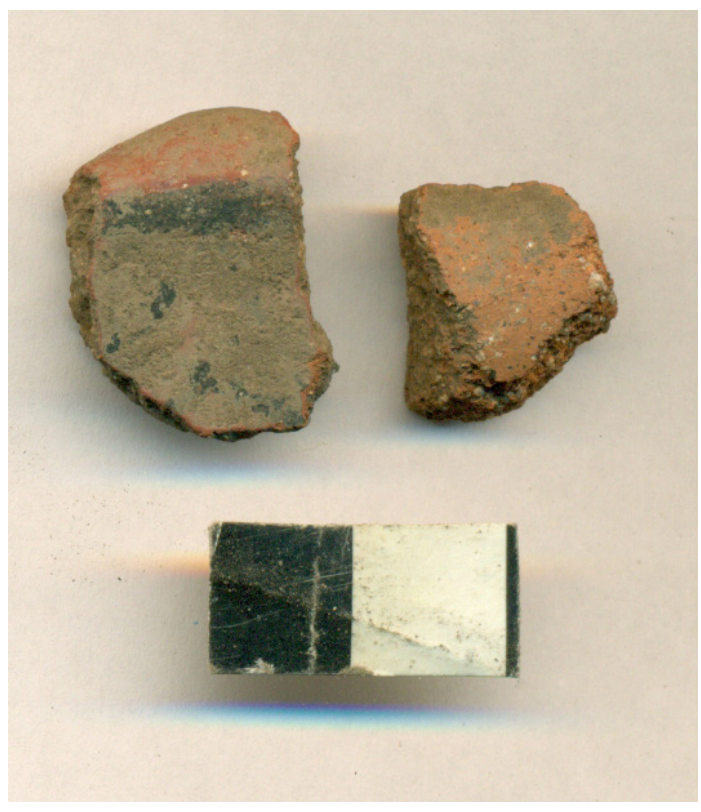

Figura 9. Protuberancia en el borde de un plato ornitomorfo (izq.) y un posible fragmento tipo Aconcagua Salmón (der.). Proceden de C-45, nivel 1.

Bump on the edge of a plate ornithomorphic (left) and a possible fragment type Aconcagua Salmon (right). They come from C-45, level 1.

de los antiplásticos que sugieren una tradición alfarera común (Dávila 2015).

\section{Lítico (Tabla 4)}

El material lítico está escasamente representado en la plataforma-ushnu. Destaca una punta de proyectil triangular pequeña, con aletas, típica del período Tawantinsuyu. Se encuentra junto a C-18, un área de concentración de material cerámico. Es muy similar a una hallada por el arqueólogo Nico Ruano durante la misma campaña de terreno, en la ladera norte, en el lado exterior de la plaza intramuros. Un raspador formal se encontró en C-45. Estos tres artefactos son elaborados a partir de la misma materia prima, sílex. En esta cuadrícula, además, aparece un desecho de talla de cuarzo lechoso. Estos dos últimos restos líticos se localizan en una cuadrícula que presenta bastante material cerámico, compartiendo un mismo proceso de formación del sitio (Figura 10).

\section{Cantos rodados (Tabla 5)}

Las piedras rodadas se concentran en cinco sectores de la plataforma. Un sector corresponde al agujero central con 31 piedras. El segundo sector está formado por las cuadrículas inmediatas por el sur del pozo central con 46 piedras. El tercero, por cuadrículas más alejadas en dirección sur del pozo central con 48 piedras. Este aumento de la cantidad de piedras a medida que se alejan del pozo central se explica por la dirección que siguió el vaciamiento natural de la plataforma, donde las piedras del interior del pozo habrían descendido por gravedad. Las cinco cuadrículas que rodean el pozo central por el norte y este presentan en total ocho piedras rodadas, confirmando que la mayor cantidad de piedras se encontraba al interior del agujero.

El cuarto con acumulación de piedras rodadas corresponde a la parte inferior de la rampa, donde tres cuadrículas concentran 113 piedras, lo que se explica por caída de material por gravedad, a través del talud de la rampa, acumulándose a sus pies en el punto de encuentro con el muro perimetral. El 
Tabla 4. Descripción de los artefactos líticos encontrados en la plataforma-ushnu de Chena. Description of lithic artifacts found in the Chena ushnu-platform.

\begin{tabular}{|c|c|c|c|}
\hline Cuad. & $\begin{array}{l}\text { Prof. } \\
(\mathrm{cm})\end{array}$ & Cantidad & Descripción \\
\hline 17 & $30-40$ & 1 & $\begin{array}{l}\text { Punta de proyectil completa de sílex color blanco con veteado gris de muy } \\
\text { buena calidad para la talla, tamaño rango } 6 \text {, sección biconvexa, forma triangular, } \\
\text { bordes rectos, base escotada, percusión blanda y por presión, mientras que } \\
\text { la extensión de este es bifacial. Esta pieza es poco espesa, siendo el ángulo } \\
\text { de su filo } 15^{\circ} \text { y dimensiones } 25 \text { x } 10 \text { x } 3 \text { mm (Figura } 10 \text {, izq). }\end{array}$ \\
\hline 45 & $0-10$ & 1 & $\begin{array}{l}\text { Raspador formal completo de sílex color café rojizo de muy buena calidad } \\
\text { para la talla, tamaño rango } 4 \text {, sección cóncavo-convexa, forma subtriangular, } \\
\text { bordes rectos, percusión dura y blanda, extensión facial marginal doble, } \\
\text { espesor medio con un ángulo de su filo } 30^{\circ} \text {. Es utilizado en todos sus bordes } \\
\text { y parece que se elabora a partir de una preforma de bifaz, dimensión } 24,6 \times \text { x } \\
2,7 \text { x 5,61 mm (Figura 10, al centro). } \\
\text { Desecho de talla de cuarzo lechoso de buena calidad, con fracturas relativamente } \\
\text { nuevas, dimensiones } 18,67 \text { x } 11,46 \times 8,2 \mathrm{~mm} \text {. }\end{array}$ \\
\hline Ladera norte & Superficie & 1 & $\begin{array}{l}\text { Punta de proyectil de sílex color verde grisáceo, de muy buena calidad para la } \\
\text { talla, tamaño rango } 6 \text {, sección biconvexa, forma triangular alargada estilizada, } \\
\text { bordes levemente cóncavos, base escotada, astillamiento por percusión } \\
\text { blanda y presión, con extensión bifacial, con ángulo de filo inferior a } 10^{\circ} \text {, } \\
\text { con dimensiones } 30,4 \text { x 9,0 x 3,6 mm (Figura 10, der.) }\end{array}$ \\
\hline
\end{tabular}

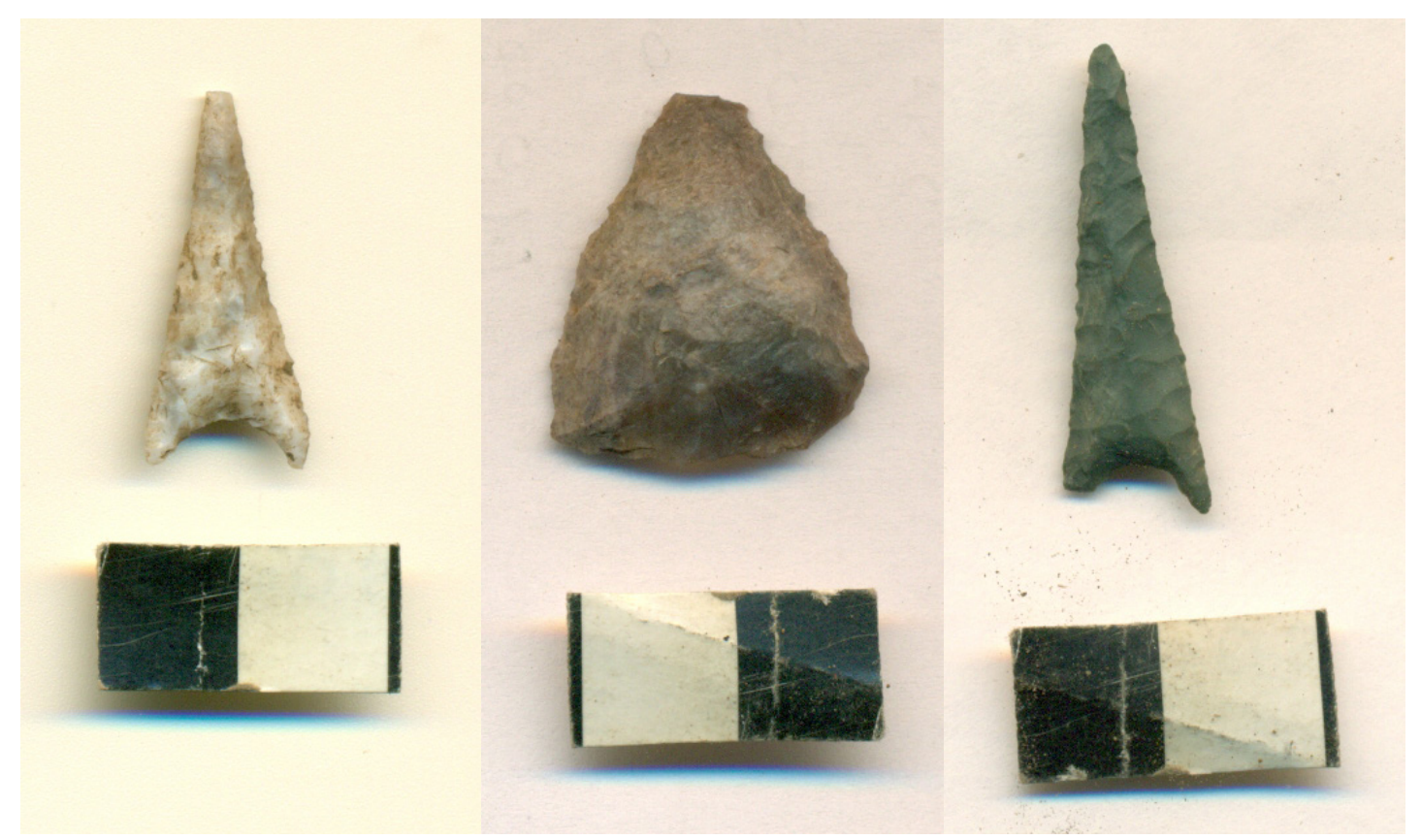

Figura 10. Puntas de proyectil triangulares pequeñas con base escotada del período Tawantinsuyu de C-17 (izq.) y hallazgo superficial de la ladera norte (der.). Al medio un raspador formal de C-45.

$S$ mall triangular projectile points with notched base period Tawantinsuyu C-17 (left) And surface finding of the northern slope (right). At noon a formal scraper $C-45$. 
Tabla 5. Distribución de las piedras rodadas al interior de la plataforma-ushnu.

Distribution of rounded cobble stones found inside the ushnu-platform.

\begin{tabular}{|c|c|c|}
\hline Cuadrícula & $\begin{array}{c}\text { Cantidad de } \\
\text { piedras rodadas }\end{array}$ & Localización \\
\hline 19 & 1 & \multirow{3}{*}{ Pozo central } \\
\hline 24 & 12 & \\
\hline 18 & 18 & \\
\hline 16 & 3 & \multirow{3}{*}{ Al sur del pozo central } \\
\hline 23 & 24 & \\
\hline 28 & 19 & \\
\hline 17 & 6 & \multirow{3}{*}{ Más al sur del pozo central } \\
\hline 22 & 15 & \\
\hline 27 & 27 & \\
\hline 20 & 4 & \multirow{5}{*}{$\begin{array}{l}\text { Cuadrículas inmediatas al } \\
\text { norte y este del pozo central }\end{array}$} \\
\hline 25 & 1 & \\
\hline 13 & 3 & \\
\hline 14 & 0 & \\
\hline 15 & 0 & \\
\hline 45 & 36 & \multirow{3}{*}{ Parte inferior de la rampa } \\
\hline 46 & 46 & \\
\hline 48 & 31 & \\
\hline 40 & 46 & $\begin{array}{c}\text { Parte media superior } \\
\text { de la rampa }\end{array}$ \\
\hline
\end{tabular}

quinto sector corresponde a una zona acotada de la rampa que presenta 46 piedras rodadas (Figura 11).

\section{Gravas (bolones) (Tabla 6)}

Del total de siete clastos tamaño grava encontrados en la estructura, cuatro se encuentran al interior de la plataforma y tres en la rampa (Figura 12). Los correspondientes a la plataforma se localizan hacia el lado sur del agujero central, mientras que los de la rampa se emplazan en el sector superior central y en su extremo norte. Seis de ellos no presentan modificaciones intencionales a la simple observación. Sin embargo, el clasto procedente de C-35 se diferencia claramente de las anteriores, motivo por el cual es objeto de un análisis especial (Figura 13).

Corresponde a un clasto de roca granítica, tamaño grava, que presenta redondez tipo tabular subesférica, de aspecto general ovoide alargado, con erosión de origen fluvial. $\mathrm{Su}$ espesor corresponde a 11,5 cm; su perímetro mayor es de $92 \mathrm{~cm}$ y menor de $80 \mathrm{~cm}$, su peso es de $17.400 \mathrm{gr}$, su volumen de $6.500 \mathrm{~cm}^{3}$, y su densidad absoluta de $2,68 \mathrm{~g} / \mathrm{cm}^{3}$. Posee color blanquecino, aunque impregnado superficialmente de un sedimento fino de color marrón. Tiene una
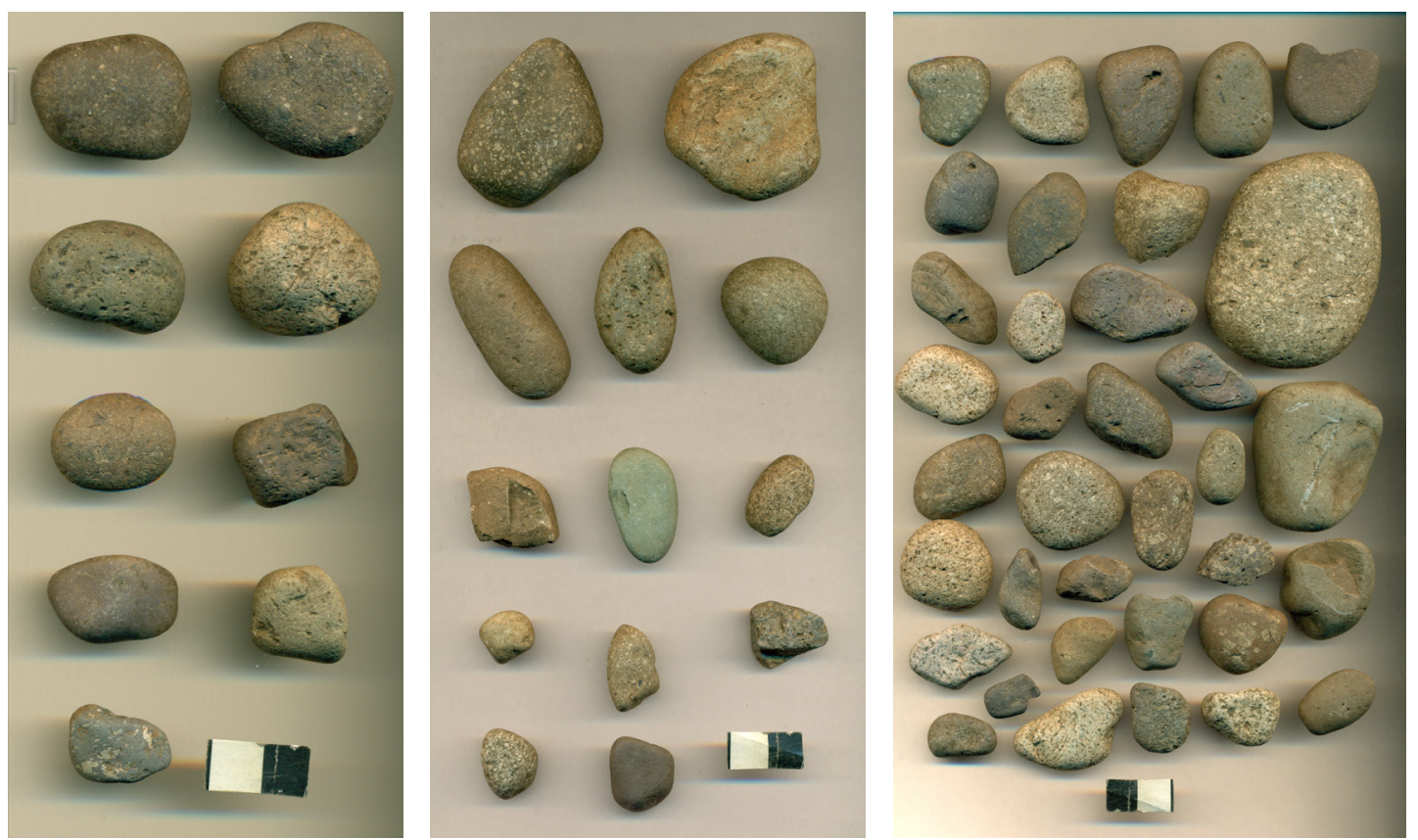

Figura 11. Piedras rodadas pequeñas encontradas en C-45 (izq.), C-23, nivel 4 (centro) C-40, nivel 3 (der.).

Found in small stones rolled C-45 (left), C-23, level 4 (middle) C-40, level 3 (right). 


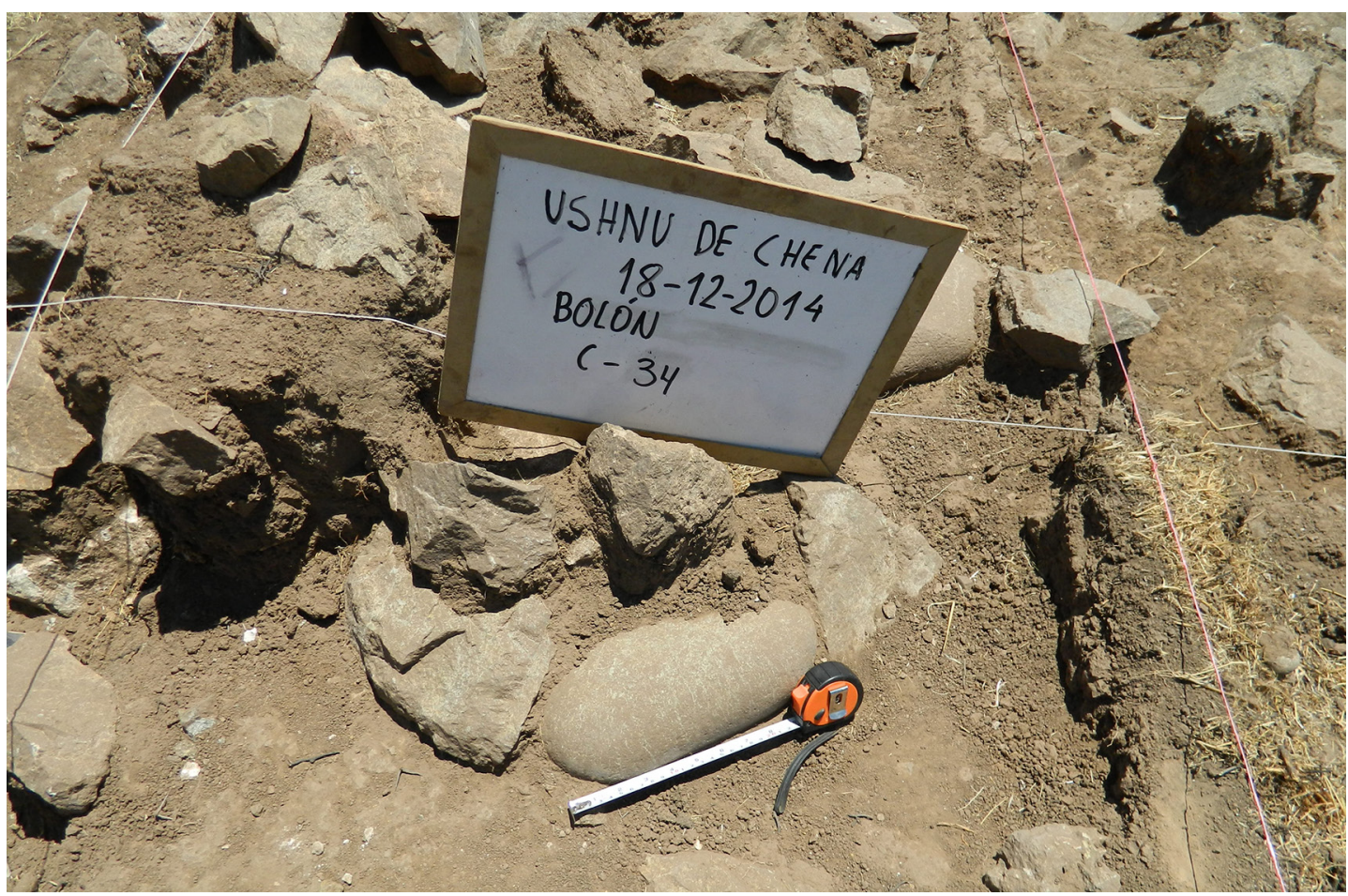

Figura 12. Bolón encontrado en C-34.

Big boulder found in C-34.

Tabla 6. Distribución de clastos (bolones) al interior de la plataforma-ushnu. Distribution of the large cobble stones found inside the ushnu-platform.

\begin{tabular}{cccc}
\hline Cuadrícula & Cantidad & $\begin{array}{c}\text { Dimensión } \\
\text { largo y ancho }(\mathrm{cm})\end{array}$ & Localización \\
\hline 13 & 1 & 40 y 23 & Inmediato al SW del pozo central \\
\hline 17 & 1 & 45 y 22 & Al S del pozo central \\
\hline 23 & 1 & 41 y 24 & Al S del pozo central \\
\hline 26 & 1 & 24 y 15,5 & Inicio de rampa, sector central \\
\hline 34 & 1 & 29 y 12 & Extremo $N$ de rampa \\
\hline 43 & 1 & 23 y 21 & Inicio de rampa, sector central \\
\hline
\end{tabular}

vetilla subdiagonal de color grisáceo que atraviesa diagonalmente la cara anterior cercana a la base y por el borde derecho (Figura 13).

Corresponde a una falla que se manifiesta como una grieta bien soldada por la cara posterior, sin relleno grisáceo. Al microscopio, su superficie presenta pulimiento diferencial en sus costados, lo cual difícilmente puede explicarse por causas naturales. Si bien no se identifican microscópicamente huellas de abrasión (p.ej. rayas o pulimento) asociadas al artefacto, principalmente debido a que presenta demasiado sedimento fino impregnado y su grano es muy grueso, son perceptibles diferencias por tacto en la superficie (Figura 14). Este bloque fue transportado especialmente para su uso o emplazamiento en el lugar, desde una situación más baja en el piso del valle y, con mucha probabilidad, asociado a 

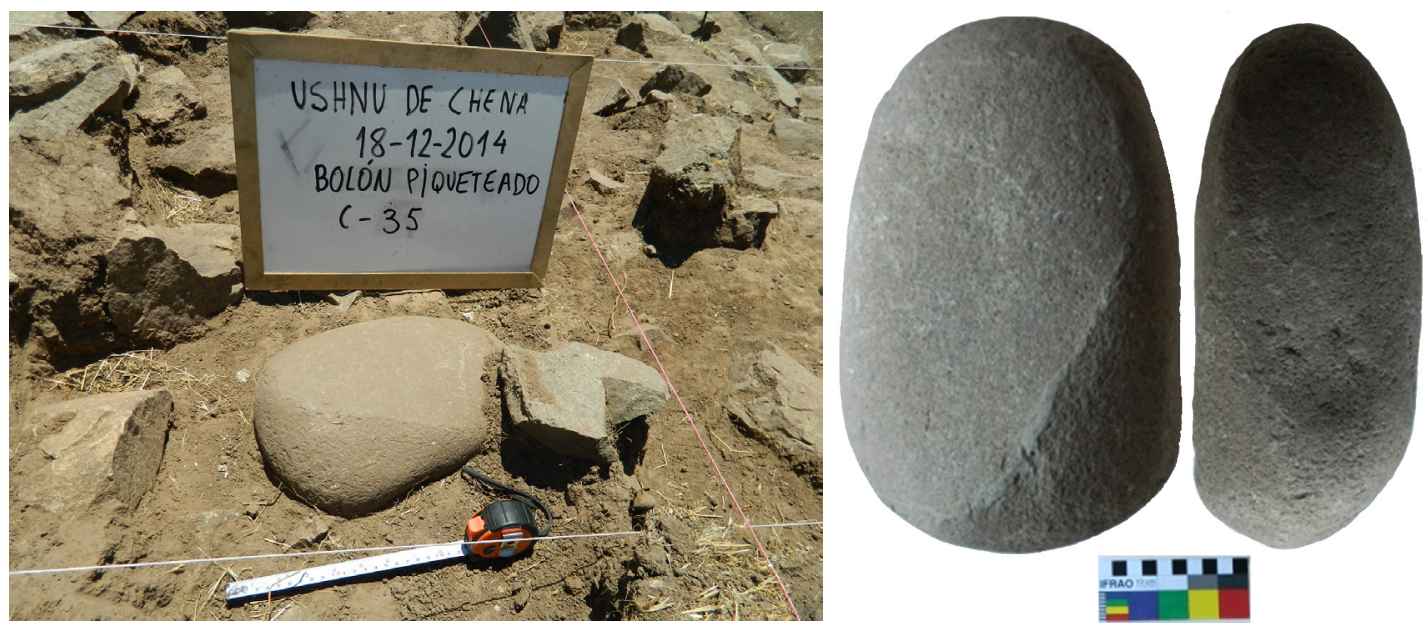

Figura 13. Bolón con vetilla y piqueteado lateral (C-35, nivel 1)

Big boulder with natural vein and side staking or picking (C-35, level 1).
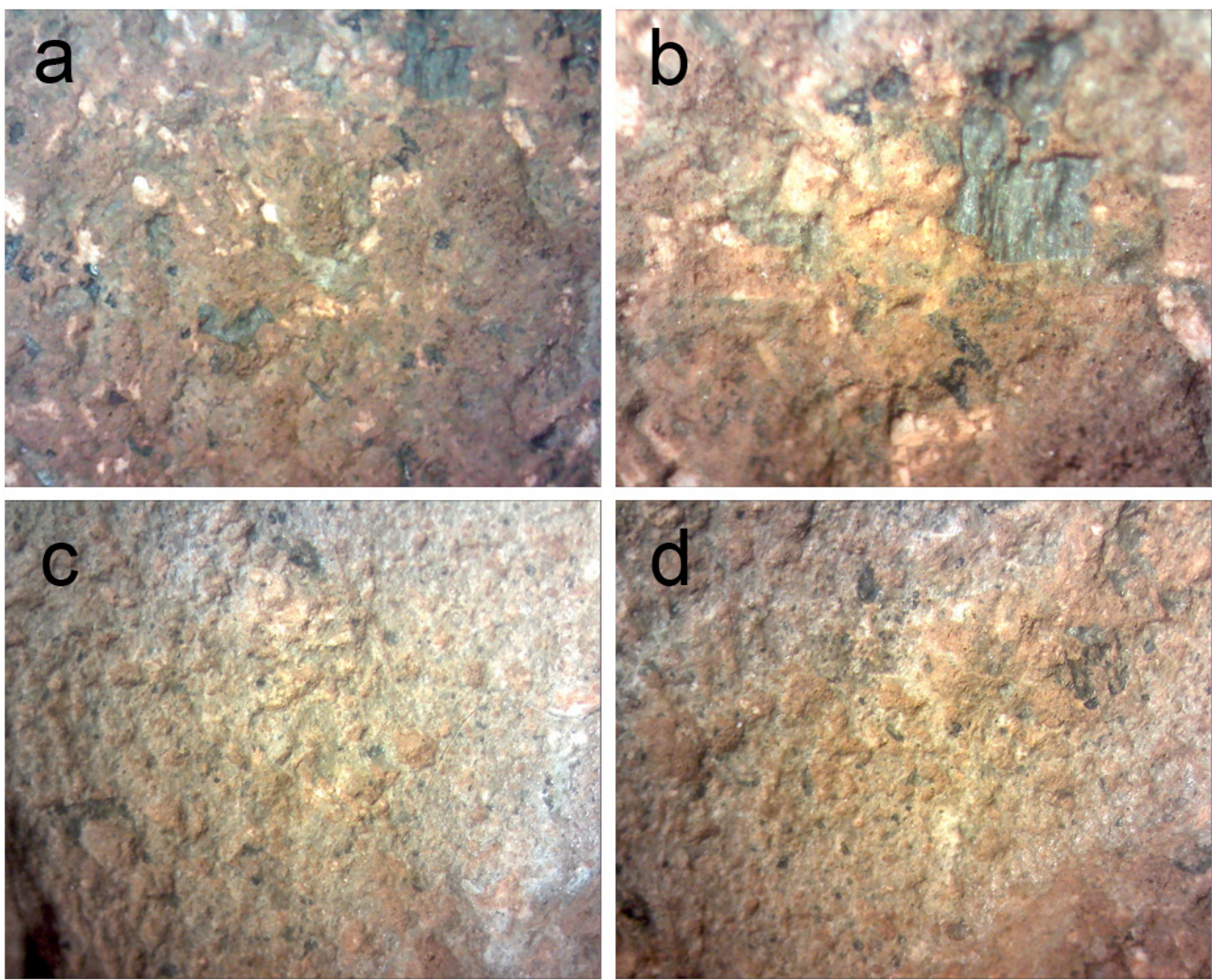

Figura 14. Fotografías microscópicas del clasto de C-35: (a) cara anterior con aumento 10x, (b) cara anterior con aumento 20 $\mathrm{x}$, (c) veta con aumento 20x y (d) superficie pulida con aumento 10x.

Microscopic photographs of the cobble stone from Unit C-35: (a) frontal view magnified 10x, (b) frontal view magnified 20x, (c) mineral vein magnified $20 x$, and (d) polished surface magnified $10 x$. 
un importante curso de agua, dada su masividad (Blanco 2016).

El interés en esta pieza radica en la posibilidad de que constituya una de las piedras sagradas de forma de "pan de azúcar" o similar a lo largo del Tawantinsuyu y que son mencionadas continuamente por los cronistas:

Hay otra guaca general en los caminos reales y en las plazas de los pueblos que llaman uznos. Eran de figura de un bolo hecho de muchas diferencias de piedras o de oro y de plata... (Albornoz en Duviols 1967:24; el destacado es nuestro).

Este tema se retomará y analizará en la discusión.

\section{Toba (Tabla 7)}

Un elemento interesante lo constituye la presencia de toba (roca piroclástica alterada, escasa en el cordón de Chena). Del total de 25 trozos encontrados, 21 (84\%) se localizan al interior del pozo central y 4 $(16 \%)$ inmediatamente al sur de este (Figura 15). Constituyen una ofrenda importante y su distribución apoya fuertemente la hipótesis que existe en el lugar un pozo central, donde estas piezas son depositadas.

\section{Restos malacológicos}

Debido a que los choritos de agua dulce hace muchos años que desaparecieron de los esteros cercanos de la zona, pueden legítimamente atribuirse a ofrendas del período Tawantinsuyu. Respecto de los restos marinos, es posible que correspondan a alimentos dejados por los visitantes del parque, con

Tabla 7. Distribución de toba al interior de la plataforma-ushnu.

Distribution of toba rocks inside the ushnu-platform.

\begin{tabular}{ccc}
\hline Cuadrícula & $\begin{array}{c}\text { Cantidad } \\
\text { de toba }\end{array}$ & Localización \\
\hline 18 & 9 & Inmediato al sur del pozo central \\
\hline 19 & 4 & Interior del pozo central \\
\hline 20 & 7 & Pared norte del pozo central \\
\hline 24 & 1 & Interior pozo central \\
\hline 22 & 1 & Al sur del pozo central \\
\hline 23 & 1 & Inmediato al sur del pozo central \\
\hline 17 & 2 & Al sur del pozo central \\
\hline
\end{tabular}

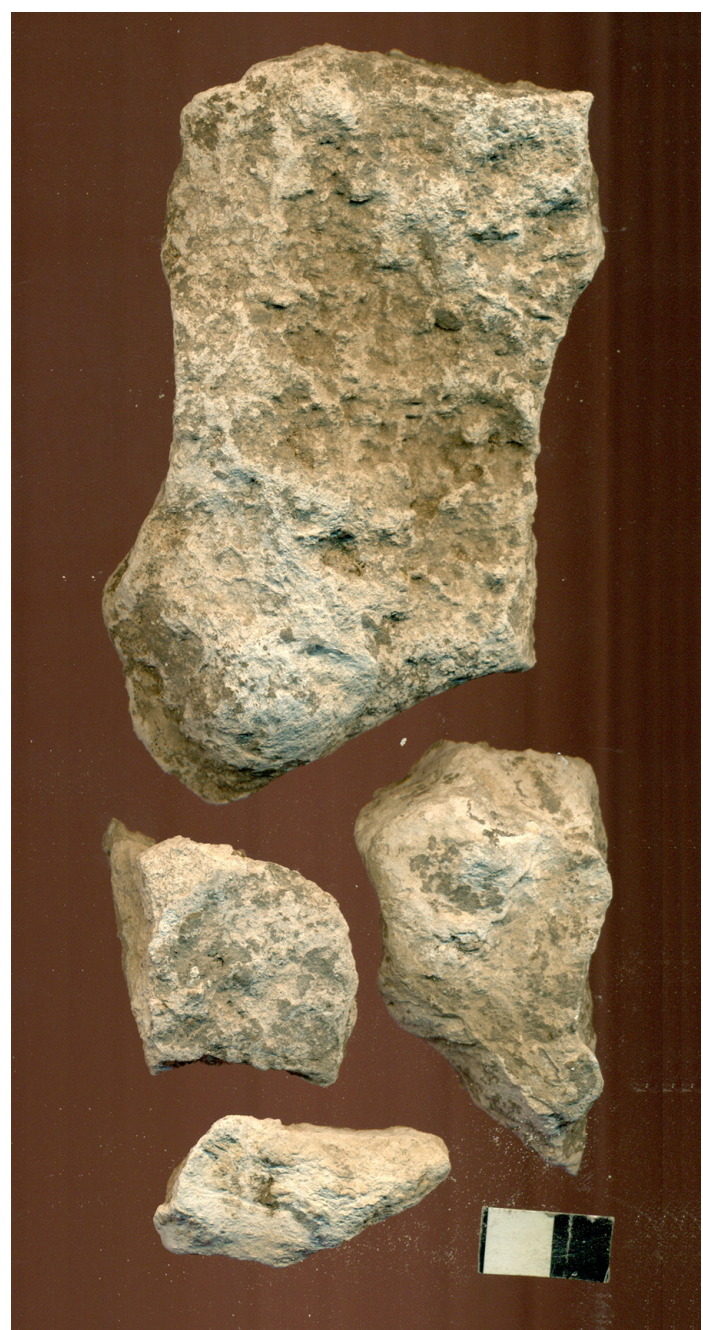

Figura 15. Restos de toba volcánica presentes en C-18. Remains of tuff present in C-18.

posterioridad a su apertura en diciembre de 1977 (Figura 16, Tabla 8).

\section{Restos óseos faunísticos (Tabla 9)}

De 12 restos óseos, los más significativos son los dos fragmentos correspondientes a camélidos (Figura 17). Uno de ellos se localiza inmediato al SE del pozo central y tiene huellas de corte. El otro se ubica en C-35, junto al clasto con huellas de piqueteado y pulimento.

\section{Pigmento}

Aunque se trata de un solo caso (Figura 18), su presencia es significativa porque la muestra es 

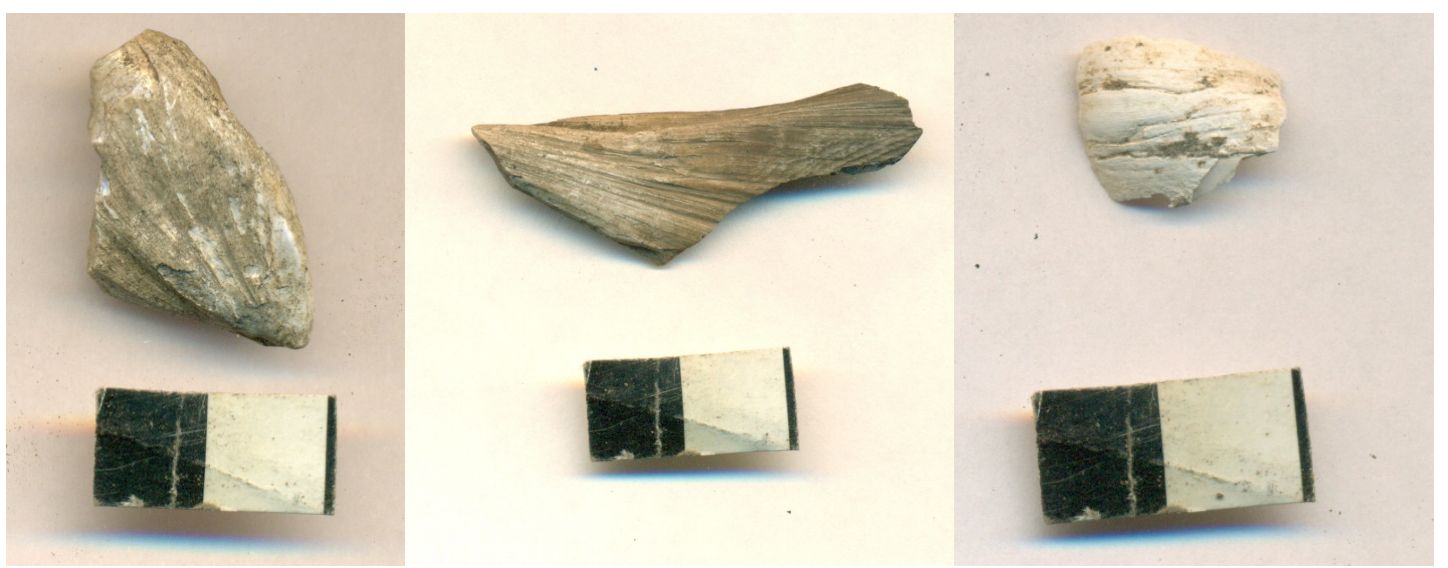

Figura 16. Restos malacológicos de C-B, nivel 1 (izq.), C- 47, nivel 1 (centro) y C-J, nivel 1 (der.).

CB malacological remains, level 1 (left.), C-47, level 1 (middle) and CJ, level 1 (right).

Tabla 8. Distribución de moluscos de agua dulce y salada al interior de la plataforma-ushnu Distribution of fresh water and marine mussels inside the ushnu-platform.

\begin{tabular}{ccccc}
\hline Cuad. & Prof. (cm) & Cantidad & Descripción & Localización \\
\hline 27 & $35-45$ & 1 & Concha de Diplodon sp. (chorito de agua dulce) & Al SE del pozo central \\
47 & $0-10$ & 1 & Concha de Mesodesma donasium (macha) & Base de la rampa \\
B & $20-30$ & 1 & Concha de Aulacomya atra (cholga) & Al NE del pozo central \\
D & 10 & 1 & Concha de Diplodon sp. (chorito de agua dulce) & Al NE del pozo central \\
\hline
\end{tabular}

Tabla 9. Distribución de los restos óseos faunísticos al interior de la plataforma-ushnu. Distribution of animal bones inside the ushnu-platform.

\begin{tabular}{ccccc}
\hline Cuad. & $\begin{array}{c}\text { Prof. } \\
(\mathrm{cm})\end{array}$ & Cantidad & Descripción de los fragmentos óseos & Localización \\
\hline 1 & $18-30$ & 3 & Astillas de hueso de posible ave & Extremo SW de la estructura \\
\hline 4 & $0-10$ & 1 & Sin identificar & Extremo W de la estructura \\
\hline 5 & $0-10$ & 1 & Sin identificar & Extremo E de la estructura \\
\hline 9 & $28-40$ & 2 & Sin identificar & Al E del pozo central \\
\hline 21 & $20-40$ & 2 & Sin identificar & Al S del pozo central \\
\hline 28 & $5-15$ & 1 & $\begin{array}{c}\text { Húmero distal derecho de camélido (por tamaño } \\
\text { cóndilos desarticular }\end{array}$ & Al SE del pozo central \\
\hline 35 & $40-50$ & 1 & Hueso largo, posiblemente camélido & Parte superior y central de la rampa \\
\hline H & $20-30$ & 1 & Animal pequeño, indeterminado & Sector superior y N de la rampa \\
\hline
\end{tabular}




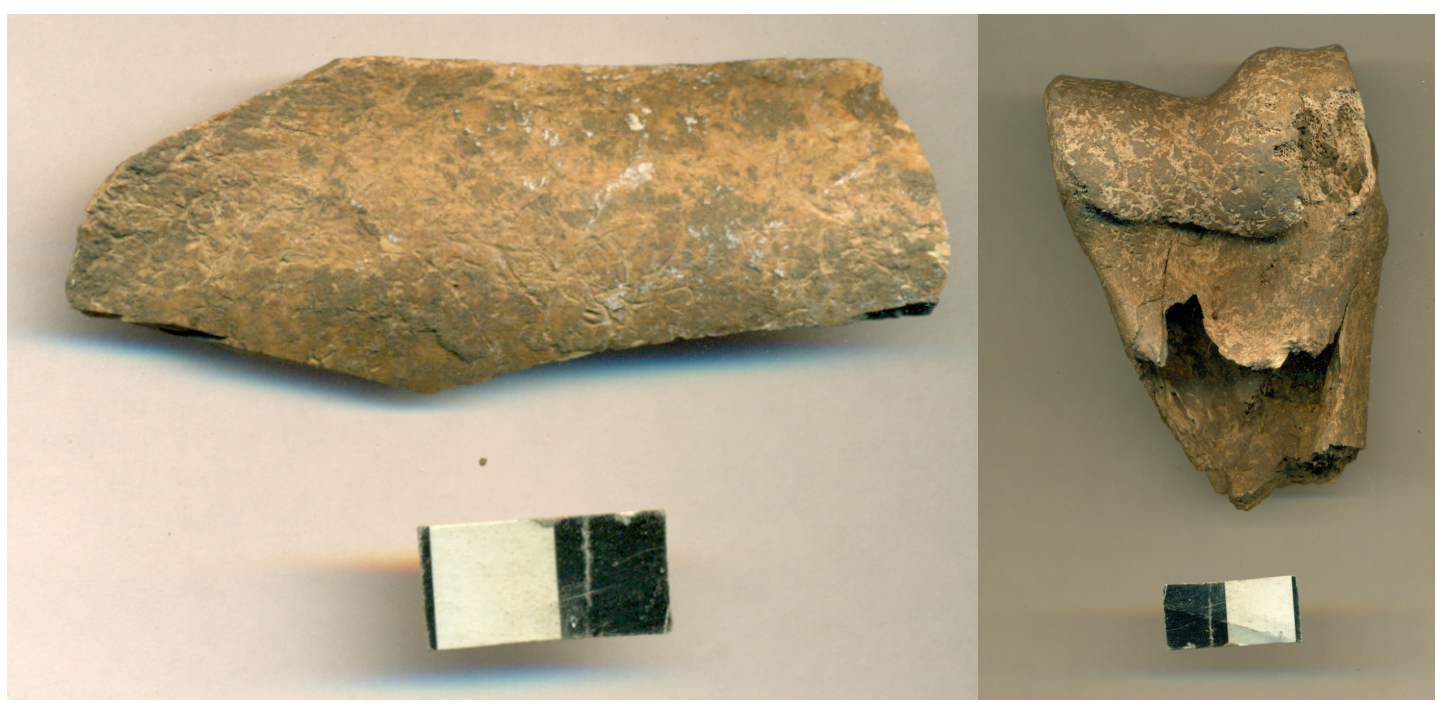

Figura 17. Restos de camélidos, posiblemente llama o guanaco (C-28, nivel 1 (izq.) y C-35, nivel 4 (der). $R$ emains of camels, llama or guanaco possibly $(C-28$, level 1 (left) and C-35, level 4 (right).

alóctona y se relaciona con una posible ofrenda o con actividades ceremoniales realizadas en el sitio (Tabla 10).

\section{Metal, vidrio, plástico}

Corresponden, en su totalidad, a restos subactuales, pertenecientes a los visitantes que concurren al parque Pucará de Chena a partir de su inauguración, en diciembre de 1977, hecho apoyado por el hallazgo de monedas correspondientes a los años 1978 y 2005 (C-18, entre 30 y $40 \mathrm{~cm}$ de profundidad) y 1981 (C-F, entre 5 y $20 \mathrm{~cm}$ de profundidad).

\section{Dataciones absolutas por termoluminiscencia}

Los resultados a partir de dos muestras cerámicas se muestran en la Tabla 11 (año base 2015). Un

Tabla 10. Distribución de pigmento amarillo (azufre) al interior de la plataforma-ushnu. Distribution of yellow pigment (sulphur) inside the ushnu-platform.

\begin{tabular}{ccccc}
\hline Cuad. & $\begin{array}{c}\text { Prof. } \\
(\mathrm{cm})\end{array}$ & Cantidad & Descripción & Localización \\
\hline 27 & $15-25$ & 1 & Trozo de pigmento amarillo (azufre) & Al SE del pozo central \\
\hline
\end{tabular}

Tabla 11. Dataciones TL de fragmentos cerámicos encontrados en la estructura excavada. Thermo-luminescence dates of pottery sherds found in the excavated structure.

\begin{tabular}{|c|c|c|c|c|c|c|}
\hline Muestra & No & Descripción & $\mathrm{P}(\mathrm{Gy})$ & D (Gy/año) & Edad (años a.p.) & Fecha \\
\hline UCTL 2852 & 1 & $\begin{array}{l}\text { Cuadrícula 14, nivel -10 parejo. } \\
\text { Fragmento rojo pintado exterior, } \\
\text { café anaranjado interior, antiplástico } \\
\text { cuarzo, fino, bien distribuido, } \\
\text { cocción oxidante pareja, } 6,3 \mathrm{~mm} \text {. }\end{array}$ & $1,77 \pm 0,13$ & $3,47 \times 10^{-3}$ & $510 \pm 50$ & 1505 a.C. \\
\hline UCTL 2853 & 2 & $\begin{array}{c}\text { Cuadrícula } 51 \text {, nivel 2, }-65 \text { a }-75 \\
\text { profundidad. Fragmento alisado } \\
\text { ambas caras, color café-anaranjado, } \\
6,6 \mathrm{~mm} \text { grosor. }\end{array}$ & $1,84 \pm 0,14$ & $3,52 \times 10^{-3}$ & $525 \pm 45$ & 1490 d.C. \\
\hline
\end{tabular}




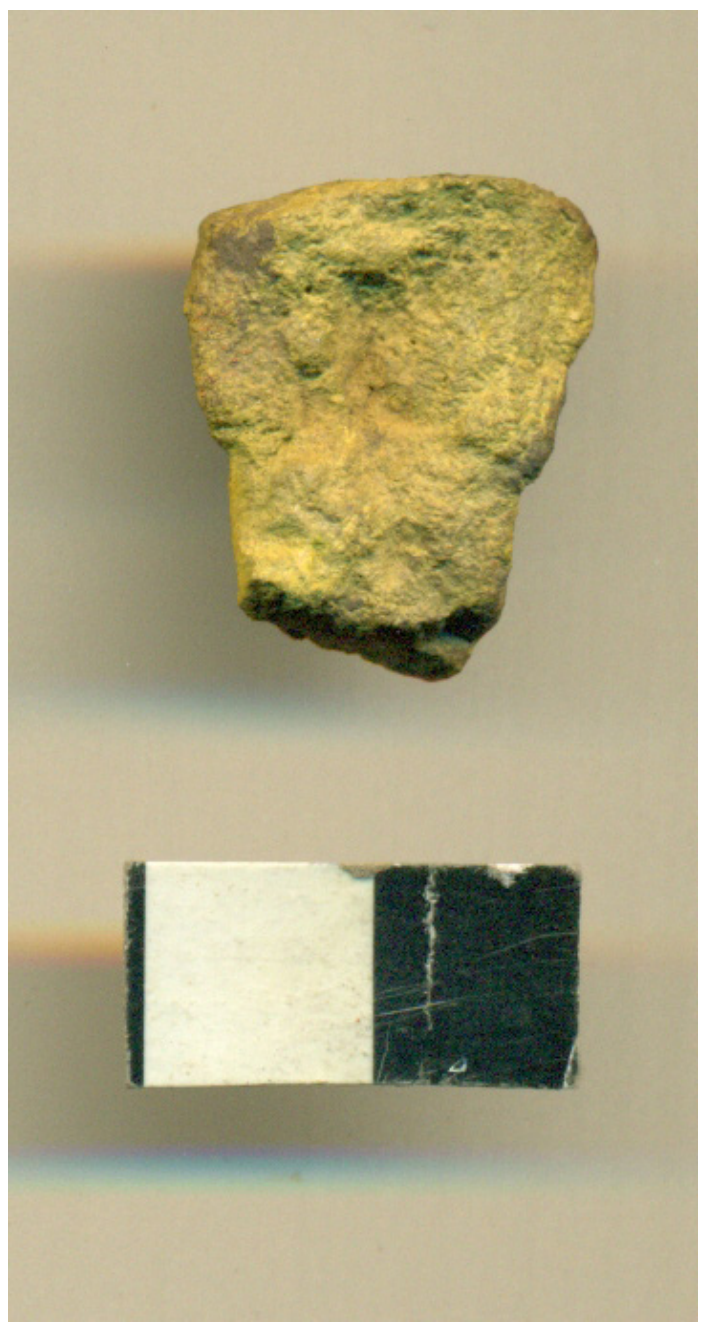

Figura 18. Pigmento amarillo (azufre) encontrado en C-27, nivel 2. $Y$ ellow pigment (sulfur) found in C-27, Level 2.

fragmento alfarero procede del interior de la estructura y el otro en la base de la rampa, colindante con el muro perimetral de la plaza. Ambos fechados están dentro del rango esperado y señalan una ocupación claramente anterior a la presencia hispana del área. Esto es confirmado por la ausencia total de materiales del período Colonial en el sitio.

\section{Discusión y Conclusiones}

Las excavaciones arqueológicas practicadas en el montículo no proporcionaron evidencias del muro de contención en la parte sur mencionado por Hans Niemeyer y R. Bobadilla, en 1957, pero sí se halló el emplantillado de grandes piedras de 30 y $40 \mathrm{~cm}$ reconocido por ellos. En efecto, una amplia masa de piedras rellena con sedimento limoso compuesto por $51 \%$ de fragmentos clásticos aparentemente obtenidos del mismo cerro fue develándose durante nuestra excavación, hasta alcanzar una extensión aproximada de $6,5 \mathrm{~m}$ x 6,5 $\mathrm{m}$ y una altura máxima de $0,60 \mathrm{~m}$. El rasgo fue interpretado como la estructura interna de una plataforma simple, de un bloque. Sobre esta estructura debió existir una capa de tierra de $0,10 \mathrm{~m}$ a $0,20 \mathrm{~m}$ de espesor que sirvió de piso, de tal manera que la altura máxima de la plataforma no debió superar los $0,80 \mathrm{~m}$ de altura (Figura 19). La mitad sur estaba seriamente dañada por la acción natural del intemperismo, los sismos y las raíces de grandes arbustos leñosos (espino), con pérdida de material por efecto de la gravedad. Posibles restos de la excavación practicada por Niemeyer y Bobadilla se observaron en la mitad NE de la plataforma.

En el extremo oriente de esta estructura arquitectónica, el emplantillado inició un descenso pronunciado ( $30^{\circ}$ aproximadamente) de unos $7,0 \mathrm{~m} \mathrm{x}$ 2,5 m de extensión, que se extendió hasta empalmar con el muro perimetral oriente de la plaza, el cual fue interpretado como la rampa posterior de la plataforma. Este rasgo era habitual de encontrar en la parte posterior o anterior de las plataformas ushnu del Tawantinsuyu. La ubicación de la rampa sugirió que el acceso a la plataforma debió estar en su extremo opuesto, en su lado poniente, enfrentando la plaza, y en directa conexión con las principales vías de comunicación de la instalación (Figura 20).

Existe un alto grado de concordancia entre las características que exhibe la estructura arquitectónica de Chena y los ushnus con plataforma ceremonial encontrados en distintas partes del Tawantinsuyu. Siguiendo los criterios proporcionados por Monteverde (2010:46, 53, 56), la plataforma de Chena reúne la condición de ser la única presente en el sitio y se localiza en una plaza desde la cual salen caminos internos que sirven para desplazarse dentro del asentamiento. Asimismo, posee forma cuadrangular, rampa posterior de evacuación y aparejo rústico en piedra. No presenta escalinata de acceso, ausencia usual en plataformas menores a un metro de altura. Asimismo, reúne una circunstancia que para Hyslop es muy importante: los ushnus are present within or on the edge or principal Inka plazas (Hyslop 1990:74).

Respecto del pozo central, se encuentra en mal estado de conservación. Su existencia es inferida 


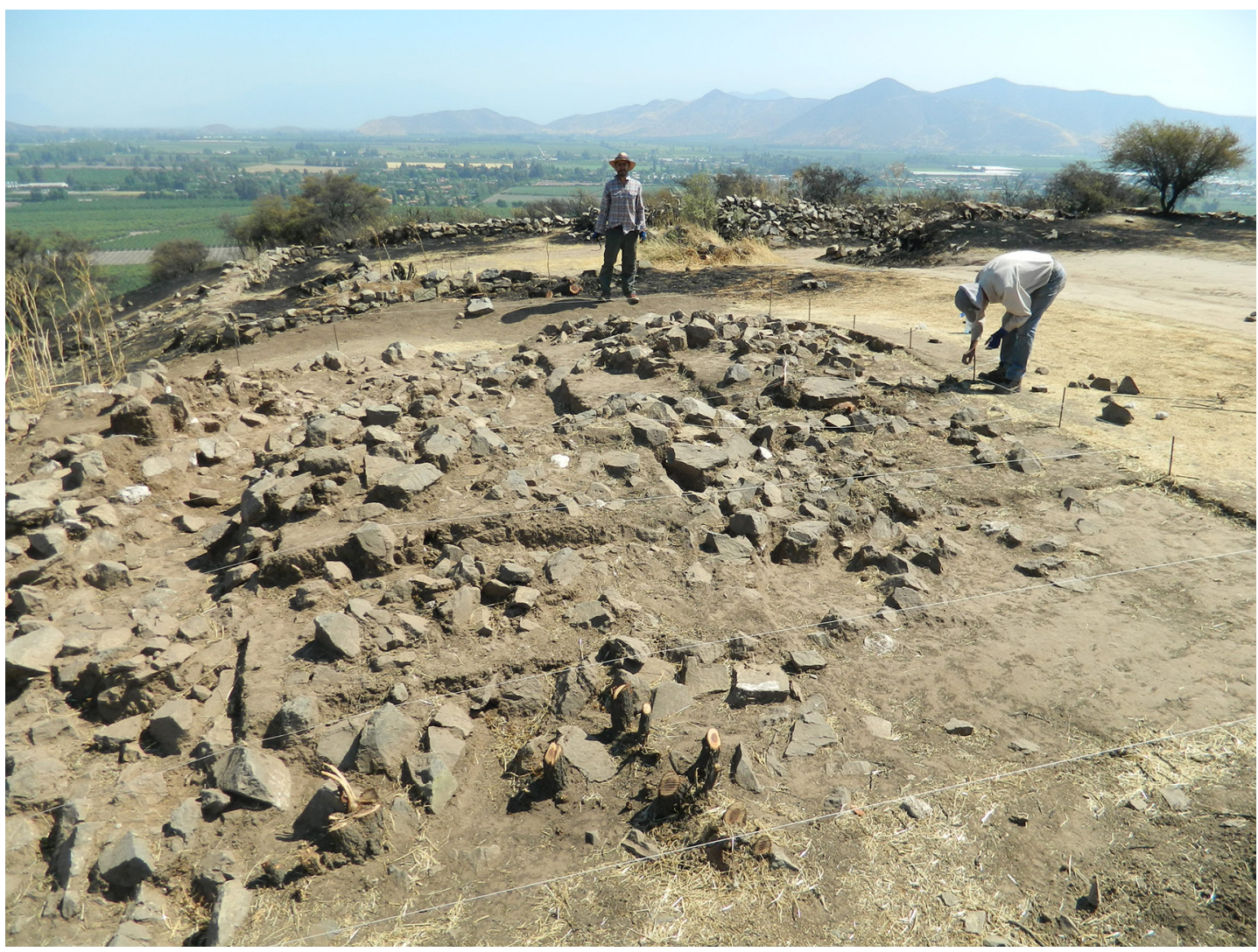

Figura 19. Vista al sur de la estructura interna de la plataforma. Southern view of the internal structure of the platform.

a partir de algunos rasgos muebles e inmuebles que permanecen en el sitio. Existe una pared rectilínea con ligera inclinación SE-NW, formada por cuatro hiladas de piedras superpuestas y $1,4 \mathrm{~m}$ de extensión, localizada en las cuadrículas 20 y 24. Es la única pared visible en la plataforma y, a partir de ella, se genera el vaciamiento por gravedad de la estructura en dirección S. Su interior conserva restos de un emplantillado de piedras en forma de L (C 19, C-24), paralelo y perpendicular al muro (Figura 7). Los restos muebles hallados en su interior y en la dirección donde se produjo el vaciamiento corresponden, en su mayoría, a cantos rodados de tamaño pequeño. Esta situación es compatible con la descripción que proporciona Monteverde (2010), donde señala que la mayoría de los ushnus se emplazan en el centro de la plataforma superior, tienen menos de un metro de profundidad, poseen planta rectangular y en su interior se halla gran cantidad de cantos rodados. A partir de esta evidencia y la existencia de toba en el lugar, se postula la existencia de un pozo central que cumplió la función de drenaje (ushnu).

Otro sector de la estructura con alta concentración de cantos rodados corresponde a la parte inferior de la rampa, en el punto de encuentro con el muro perimetral E de la plaza, situación que se explica por el descenso natural de las piedras, acumulándose estas en la base de la rampa.

La existencia de cantos rodados al interior del pozo de ofrendas es común en las plataformasushnu. En el Shinkal de Quimivil, por ejemplo, se encontraron miles de grandes guijarros traídos del río Simbolar formando parte del piso empedrado o cocha del ushnu del lugar (Raffino 1997:23, 2004:75). Para los incas simbolizan:

el ciclo natural de las lluvias que recorren verticalmente el Hanan (arriba) el Cay (al medio) y Oco pacha (abajo) a través de la construcción de pozos con cantos rodados en su interior y canales en los ushnus. 


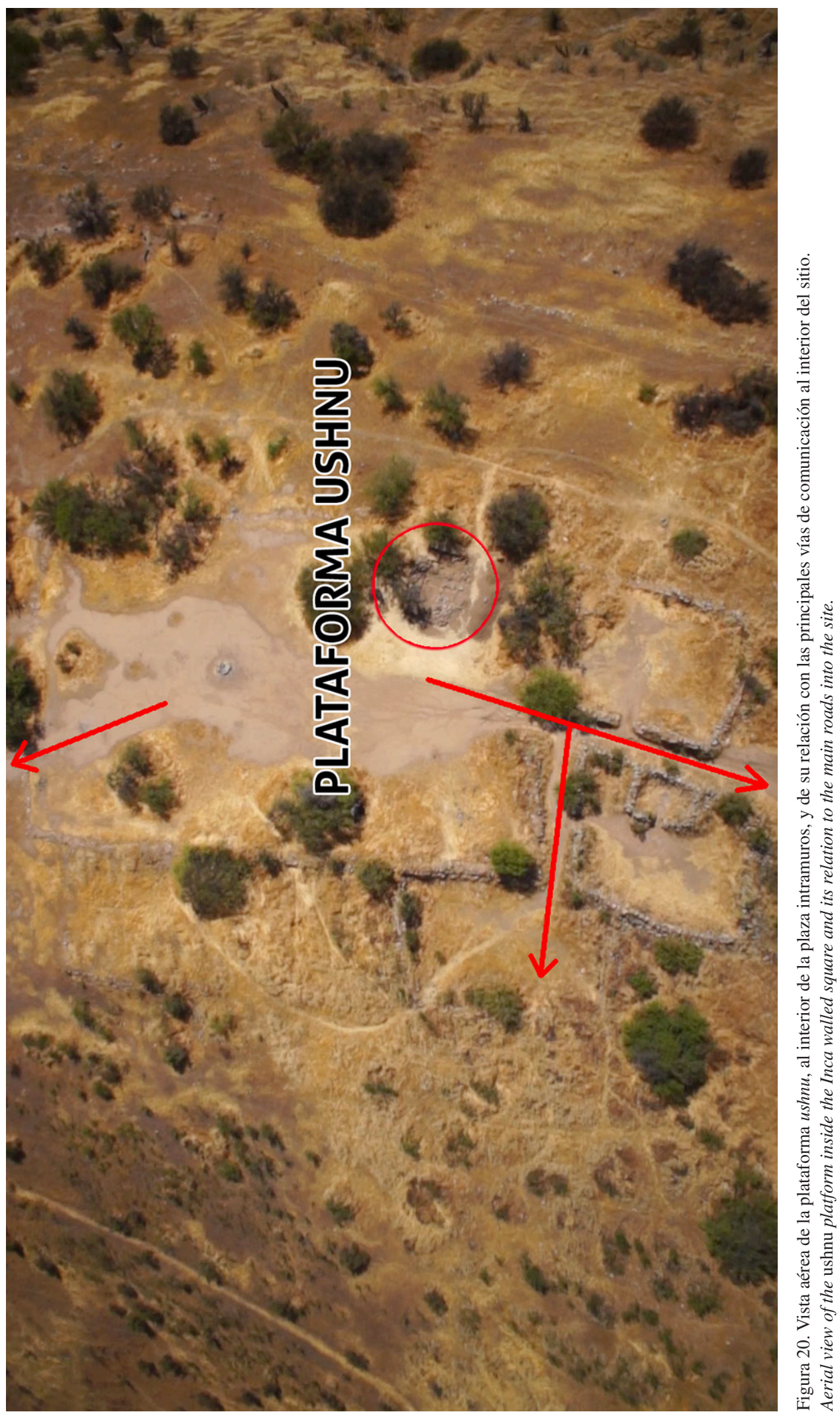


Los pozos se volvieron el eje central de los ushnus, al colocárselos al centro de la plataforma superior. $\mathrm{Al}$ mismo tiempo el ushnu pasó a ser el eje central de los asentamientos construidos durante la expansión imperial, con las ceremonias de libaciones que se practicaban en sus plazas principales (Monteverde 2010:58, 59, 72).

Etnográficamente se constata una estrecha relación entre rayos, lluvias y cantos rodados en el pensamiento andino actual.

Si llueve hay rayos, si hay lluvia hay agua en los ríos, si el caudal del agua de los ríos aumenta se originarán cantos rodados... Entonces, si hay cantos rodados es porque el agua de los ríos se ha originado, si hay buen caudal de agua en los ríos es porque ha llovido y si ha llovido es porque ha habido rayos (Monteverde 2010:65).

En otras palabras, cuando un poblador arroja cantos rodados a las lagunas o ríos, intenta reproducir simbólicamente el proceso cíclico de las lluviasrayos-cantos rodados, generándose una "asociación entre el ushnu, Illapa como creador de las aguas y la visión cosmológica de la unión de los tres planos del mundo andino (Monteverde 2010:65).

Otras ofrendas importantes en Chena lo constituyen la toba y azufre (pigmento amarillo), posiblemente traídos al sitio desde la cordillera andina, las conchas de moluscos de agua dulce (Diplodon spp.) y salada (Aulacomya atra, Mesodesma donacium) y la punta de proyectil. Cabe reiterar que los trozos de toba se concentran en la pared y piso del pozo central (84\%), lo que apoya la hipótesis de su existencia. El pigmento se localiza al sur del pozo (C-27).

Asimismo, se encuentran seis bolones de tamaño grande. Cuatro de ellos se distribuyen aguas abajo del agujero central (C-13, C-17 y C-26) y las restantes se localizan en la rampa. De acuerdo con Meddens et al. (2010:173, 1 76, 191), estas piedras están presentes en la mayoría de los ushnus, representan ancestros deificados y se relacionan íntimamente con el tiempo en que el sol descansa o se sienta y, por tanto, atañen al culto solar. Según Farrington $(2013,2014)$ : las rocas de forma cónica representan "piedras ancestros" y son desplegadas durante los momentos claves del calendario ritual. Sirven para reforzar las conexiones verticales, vinculando las divinidades celestiales con las personas del mundo contemporáneo y con el mundo de los ancestros, destacando el rol del Inca como axis mundi.

Mención especial merece el clasto con vetilla y amplio piqueteado encontrado próximo al punto de inflexión entre la plataforma y la rampa. De acuerdo con los cronistas era común la presencia de objetos de piedra sagrados en el Cusco y en las provincias:

Y para que la gente común adorasen allá fuera... hizo poner en medio de la plaza del Cuzco, donde agora es el rollo, una piedra de la hechura de un pan de azúcar, puntiaguda para arriba y enforrada de una hoja de oro... (Betanzos en Zuidema 1989:410, el destacado es nuestro).

Es posible inferir que la comparación descriptiva más frecuente de este objeto empleada por los cronistas es con los "panes de azúcar", forma cónica muy particular y bastante estandarizada en el período colonial. Esto justificaría su uso como referente formal por los cronistas (Blanco 2016).

El jarabe de azúcar o melaza concentrado y colado con un tocuyo o jerga se dejaba cristalizar en moldes de barro, que les confería esa característica forma de pan de azúcar. Esta etapa del proceso tenía lugar en la casa de la purga, hacia donde se llevaba el caldo en unos porrones de barro con capacidad para soportar una arroba y media que era la medida exacta de las hormas de barro (Salas de Coloma 1998:254, el destacado es nuestro).

El texto supra citado indica claramente que la medida de un pan de azúcar debía ser de alrededor de 17,250 kilogramos, aunque es admisible alguna variación según procedimientos de cristalización diversos. Así pues, el peso de una roca como la que se describe para los ushnu debía de rondar los 17 kilogramos. Cabe destacar la excepcional coincidencia de masa entre los ejemplos coloniales de "panes de azúcar" que se emplean como referencia literaria por los cronistas y la roca de cerro Chena. Si suponemos una gran estandarización del referente, la masa de la pieza en cuestión es 
en la práctica idéntica a la del símil empleado por los cronistas, o "una arroba y media" como se desprende de los datos posteriores. Pese a esto, se aconseja cautela, ya que la densidad del granito es con seguridad más alta que la del azúcar, por lo cual debería esperarse un objeto más voluminoso en realidad y que sus características permiten plantear a modo de hipótesis su función de "gnomon", "piedra solar" u otra de tipo simbólico, según los antecedentes, restando análisis más detenidos que podrían a futuro aportar a la discusión para dilucidar la cuestión (Blanco 2016). Este sería un hallazgo notable, si se tiene en consideración los mínimos casos en que estas piedras se han encontrado (Hyslop 1990:74, 315).

Respecto del resto de los objetos encontrados, corresponden a la parafernalia de libaciones líquidas y alimentos rituales que rodean este tipo de sitios político-ceremoniales. Destacan los restos óseos de camélidos, que por su tamaño corresponderían a llama o guanaco, las formas cerámicas abiertas útiles para servir víveres, los aríbalos para tomar y ofrendar chicha, y el material lítico, como el raspador y el desecho de talla, relacionados con la preparación de materiales, como cuero. Dos fragmentos cerámicos proporcionaron fechas coherentes: $1.490+-45$ d.C. y 1.505+-50 d.C., confirmando una ocupación prehispánica monocomponente del sitio. Estas son los primeros fechados absolutos obtenidos en Chena.

Siguiendo los lineamientos propuestos por Farrington (2013, 2014), es posible reconocer en la plataforma de Chena los siguientes dos componentes: (1) "algo que da la impresión que sube al cielo (hanan pacha)", que en el caso en estudio está representado por la plataforma y su rampa posterior, la piedra bolón con vetilla y piqueteado, las "piedras ancestros" y las piedras rodadas de río y, (2) "algo que da la impresión que entra al mundo inferior (uqhu pacha)", que en la estructura excavada corresponde al pozo central donde se efectúan las libaciones líquidas y las ofrendas como moluscos de agua dulce y salada, pigmento amarillo y toba volcánica. De acuerdo con lo anterior, se concluye que la función de la estructura estudiada corresponde a plataforma ushnu, elemento sagrado introducido por el Tawantinsuyu en sus principales instalaciones y plazas. Se constituye así en la plataforma ushnu más austral del Tawantinsuyu, emplazado en la cima del pucará de Chena, con amplio dominio sobre el curso medio del valle de Maipo, sumándose a la plataforma ushnu de cerro El Plomo, situada unos $50 \mathrm{~km}$ al ENE (Mostny 1957) y al ushnu (pozo central) de Chada (Stehberg et al. 1997; Farrington, comunicación personal, 1998), localizado $30 \mathrm{~km}$, aproximadamente, en dirección SES. Estos tres sitios están visualmente conectados entre sí.

Estos hallazgos apoyan los enfoques actuales que postulan una ocupación Tawantinsuyu marcada del valle del Mapocho-Maipo, con existencia de un centro administrativo y ceremonial principal en el actual casco histórico de la ciudad de Santiago, y un creciente proceso de intensificación hidroagrícola que abarcó gran parte de la actual Región Metropolitana (Stehberg y Sotomayor 2012).

La presencia de la plataforma ushnu obliga a redefinir la función principal asignada tradicionalmente a Chena, la cual se ha definido como sitio defensivo o pucara (Stehberg 1976), como lugar de observaciones astronómicas (Boccas et al. 1999) o como wak'a (Bustamante 1996). Ciertamente, pudieron desarrollarse cada una de estas funciones o todas ellas, sin embargo, la complejidad del sitio aumenta mucho con la presencia de esta estructura arquitectónica, que le agrega al sitio una función de carácter político-administrativo-ceremonial de dimensión estatal y de gran importancia dentro del Tawantinsuyu.

Agradecimientos: los autores agradecen a las siguientes instituciones y personas que contribuyeron a la materialización de esta investigación. Instituciones: Museo Nacional de Historia Natural (Chile), Fondo Nacional de Investigación Científica y Tecnológica (Proyecto FONDECYT 1140043/2014) y Consejo de Monumentos Nacionales. Personas: José Berenguer, José Blanco, Sebastián Contreras, Luis Cornejo, Cristián Dávila, Ian Farrington, Macarena Fernández, Leonardo Fuica, Carolina Gatica, Gustavo Gómez, Douglas Jackson, Rafael Labarca, Juan Carlos Leppe, Alexis López, Claudia Prado, Daniel Pascual, Christian Salazar, Sebastián Pérez, David Robles, Álvaro Román, Rodrigo Rojas, Nico Ruano, Omar Torres, Fernanda Torrijos, Mauricio Uribe, Marco Vargas. Asimismo, extendemos nuestro agradecimiento a los evaluadores de este artículo y al equipo editor de la revista Chungara, y en forma especial al Dr. Ian Farrington, inspirador y orientador de este trabajo. 


\section{Referencias Citadas}

Anónimo 1906 [ca. 1565]. Discurso de la sucesión y gobierno de los yngas. En Juicio de límites entre el Perú y Bolivia; prueba peruana presentada al gobierno de la República Argentina, Vol. 8, editado por V.M. Maúrtua, pp. 149-165. Tipografía de los Hijos de M. G. Hernández, Madrid.

Arriaga, P. 1920 [1621]. La extirpación de la idolatría en el Perú. Colección de libros y documentos referentes a la historia del Perú. Tomo I, segunda serie. Imprenta y Librería San Martín y Ca. Lima.

Astuhuaman, C. 2014. The Ushnu, the centre of the inca world: An overview from the highlands of Piura, northern Peru. En Inca Sacred Space, editado por F. Meddens, C. McEwan, K. Willis and N. Branch, pp. 221-231. Archetype Publications, Londres.

Blanco, J. 2016. Análisis de un artefacto lítico del "ushnu" de cerro Chena. Informe inédito en poder del autor.

Betanzos, J. 2010. Suma y Narración de los Incas [1551]. Fondo Editorial de la Unidad de Posgrado de la Facultad de Ciencias Sociales de la Universidad Nacional Mayor de San Marcos, Lima.

Boccas, M. 2004. Topografía y astronomía: dos herramientas de apoyo en arqueología. Chungara Revista de Antropología Chilena 36:1037-1044.

Boccas, M., P. Bustamante, C. González y C. Monsalve C. 1999. Promising archaeoastronomy investigations in Chile. Actas del Congreso OXFORD VI and SEAC -99, Astronomía y Diversidad Cultural Vol 1, pp. 115-123. Organismo Autónomo de Museos del Cabildo de Tenerife, Tenerife.

Branch, N., M. Frouin, R. Kemp, N. Marini, F. Meddens, Ch. Onuora y B. Silva 2014. The landscape, environment and pedosedimentary context of inca stepped platforms (ushnu), Ayacucho, Perú. En Inca Sacred Space, editado por F. Meddens, K. Willis, C. McEwan y N. Branch, pp. 99-117. Archetype Publications, London.

Bray, T. 2015. Andean Wak' as and alternative configurations of persons, power and things. En The Archaeology of Wak'as, editado por T. Bray, pp. 3-16. University Press of Colorado, Colorado.

Bustamante, P. 1996. La huaca del cerro Chena, arquitectura sagrada del pueblo Inca. Revista CIMIN (Construcción, Industria y Minería) 61:32-35.

Cieza de León, P. 1962 [1553]. La Crónica del Perú. Espasa Calpe Colección Austral, Madrid.

Coben, L. 2014. If all the world's a stage then what's an ushnu? En Inca Sacred Space, editado por F. Meddens, K. Willis, C. McEwan y N. Branch, pp. 127-132. Archetype Publications, London.

Cornejo, L. 2010. Hacia una hipótesis sobre el surgimiento de la cultura Aconcagua. Actas del XVII Congreso Nacional de Arqueología Chilena, pp. 341-350. Sociedad Chilena de Arqueología, Valdivia.

Dávila, C. 2015. Informe de pastas cerámicas pucara de Chena. Informe en poder del autor.

de Molina, C. 2008 [1574-5]. Relación de las Fábulas y Ritos de los Incas. Universidad de San Martín de Porres, Lima.
Duviols, P. 1967. Un inédit de Cristóbal de Albornoz: La instrucción para descubrir todas las guacas del Pirú y sus camayos y haziendas. Journal de la Société des Americanistes 56:7-39.

Durán, E. y M. Planella 1989. Consolidación agroalfarera: zona central (900-1470 d.C.). En Prehistoria. Desde sus Orígenes hasta los Albores de la Conquista, editado por J. Hidalgo, V. Schiappacasse, H. Niemeyer, C. Aldunate e I. Solimano, pp. 312327. Editorial Andrés Bello, Santiago.

Eliade, M. 1959. The Sacred and the Profane. The Nature of Religion. Harcourt Brace \& World, New York.

Farrington, I. 2013. Cusco. Urbanism and Archaeology in the Inka World. University Press of Florida.

Farrington, I. 2014. The centre of the world and the Cuzco ushnu complexes. En Inca Sacred Space, editado por F. Meddens, K. Willis, C. McEwan y N. Branch, pp. 197-207. Archetype Publications, London.

Farrington, I. y R. Raffino 1996. Mosoq suyukunapa tariqnin: nuevos hallazgos en el Tawuantinsuyo: inka news from around the empire. Tahuantinsuyu 2:73-77.

González, P. 2013. Arte y Cultura Diaguita Chilena. Simetría, Simbolismo e Identidad. Serie Monográfica de la Sociedad Chilena de Arqueología 2.

Hyslop, J. 1990. Inka Settlement Planning. University of Texas Press, Austin.

Llagostera, A. 2013. Prehistoria de Chile: Pueblos y Culturas Ancestrales. Instituto de Investigaciones Antropológicas, Universidad de Antofagasta, Antofagasta.

Martínez, A. y C. Salazar 2015. Informe sedimentológico de excavaciones arqueológicas en el convento Santo Domingo, Cuerpo de Bomberos de Santiago y Chena. Manuscrito en poder del autor.

Meddens, F. 2014. Boundaries at the roof of the world: the $u$ shnu and division in political and religious space. En Inca Sacred Space, editado por F. Meddens, K. Willis, C. McEwan y N. Branch, pp. 57-70. Archetype Publications, London.

Meddens, F. 2015. The importance of being inka. Ushnu platforms and their place in the andean landscape. En The Archaeology of Wak'as, editado por T. Bray, pp. 239-263. University Press of Colorado, Colorado.

Meddens, F., C. Mcewan y C. Vivanco 2010. Inca "stone ancestors" in context at a high-altitude "ushnu" platform. Latin American Antiquity 21:173-194.

Meddens, F, K. Willis, C. Mcewan y N. Branch 2014. Introduction: Inca sacred space-landscape, site and symbol in the Andes. En Inca Sacred Space, editado por F. Meddens, K. Willis, C. McEwan y N. Branch, pp. 1-4. Archetype Publications, London.

Monteverde, L.R. 2010. La configuración arquitectónica de los ushnus como espacios de libaciones y ofrendas líquidas durante el Tahuantinsuyo. Bulletin de l'Institut Francais d'Etudes Andines 40:31-80.

Monteverde, L.R. 2011. Los incas y la fiesta de la Situa. Chungara Revista Antropología Chilena 43:243-256. 
Mostny, G. 1957. La momia del cerro el Plomo. Boletín Museo Nacional de Historia Natural 27:3-127.

Moyano, R. 2010. El ushnu y la astronomía de horizonte en Viña del Cerro. Chungara Revista de Antropología Chilena 42:419-432.

Moyano, R. 2014. Astronomical observations on Inca ushnus in the southern Andes. En Inca Sacred Space, editado por F. Meddens, K. Willis, C. McEwan y N. Branch, pp. 187-196. Archetype Publications, London.

Murúa, M. 1986 [1611]. Historia General del Perú. Historia, Madrid.

Presbítero, G. 2000-2001. Plataforma ceremonial con ushnu del sitio Maucallacta. Andes 3:185-199.

Raffino, R. 1997. El ushnu del Shinkal de Quimivil. Tawantinsuyu 3:22-39.

Raffino, R. 2004. El Shinkal de Quimivil. Editorial Sarquís, San Fernando del valle de Catamarca, Catamarca.

Rodríguez, S. 2014. The link: of sacred persons and places. En Inca Sacred Space, editado por F. Meddens, K. Willis, C. McEwan y N. Branch, pp. 49-55. Archetype Publications, London.

Salas de Coloma, M. 1998. Estructura Colonial del Poder Español en el Perú. Huamanga (Ayacucho) a través de sus Obrajes, Siglos XVI-XVIII. Tomo II. Pontificia Universidad Católica del Perú, Lima.

Sánchez, R. y M. Massone 1995. Cultura Aconcagua. Colección Imágenes del Patrimonio, Centro de Investigaciones Barros Arana, Santiago.

Stehberg, R. 1976. La fortaleza de Chena y su relación con la ocupación incaica de Chile central. Publicación Ocasional del Museo Nacional de Historia Natural 23:3-37.
Stehberg, R. 1995. Instalaciones Incaicas en el Norte y Centro Semiarido de Chile. Colección de Antropología, DIBAM, Santiago.

Stehberg, R. 2006. En torno al simbolismo del pucará de Chena. Revista de Diseño Urbano y Paisaje DU\&P 9(3). Versión online: http://www.ucentral.cl/du\&p/pdf/9_pucara_chena.pdf

Stehberg, R., M. Planella y H. Niemeyer 1997. Complejidad arquitectónica de las ruinas prehispánicas de Chada en la antigua ruta entre los ríos Maipo y Cachapoal. Xama 6(11):53-64.

Stehberg, R. y G. Sotomayor 2012. Mapocho incaico. Boletín del Museo Nacional de Historia Natural 61:85-149.

Stehberg, R., G. Sotomayor y J. Cerda 2016. Mapocho incaico norte. Boletín del Museo Nacional de Historia Natural, en prensa.

Villaseca, L. y P. Ayala 1995. Relaciones interregionales en el origen y desarrollo preincaico del complejo cultural Aconcagua. Actas del XIII Congreso Nacional de Arqueología Chilena, pp. 291-299. Sociedad Chilena de Arqueología, Antofagasta.

Ziólkowski, M. 1984. La piedra del cielo: algunos aspectos de la educción e iniciación religiosa de los príncipes incas. Anthropologica 2(2):45-65.

Zuidema, T., 1979. El ushnu. Revista de la Universidad Complutense 28(117):317-362.

Zuidema, T. 1989. Reyes y Guerreros. Ensayos de Cultura Andina. FOMCIENCIAS, Lima.

Zuidema, T., 1991. La Civilización Inca en Cuzco. Fondo de Cultura Económica, México D.F.

Zuidema, T. 2014. The ushnus of Cuzco and sacred centres in andean ethnography, ethnohistory and archaeology. En Inca Sacred Space, editado por F. Meddens, K. Willis, C. McEwan y N. Branch, pp. 5-28. Archetype Publications, London.

\section{Notas}

1 El Tawantinsuyu y la Cultura Aconcagua: interacción sociocultural e ideológica durante el período tardío en la cuenca del Maipo-Mapocho.

2 Articulaciones entre instalaciones arquitectónicas, red hidráulica, caminos estatales y paisaje ritualizado en los valles de Mapocho-Maipo durante el período Tawantinsuyu.

3 Estudio realizado en el marco del proyecto FONDECYT 1140043/2014, bajo el patrocinio de la Dirección de
Bibliotecas, Archivos y Museos y el Museo Nacional de Historia Natural (Chile).

4 Leonardo Fuica.info@ fuicafoto.cl

5 Los restos arqueofaunísticos fueron analizados por Rafael Labarca; los restos líticos por Daniel Pascual; las pastas cerámicas por Cristian Dávila; el análisis sedimentológico por Alejandro Martínez y Christian Salazar y las dataciones TL por Álvaro Román. 


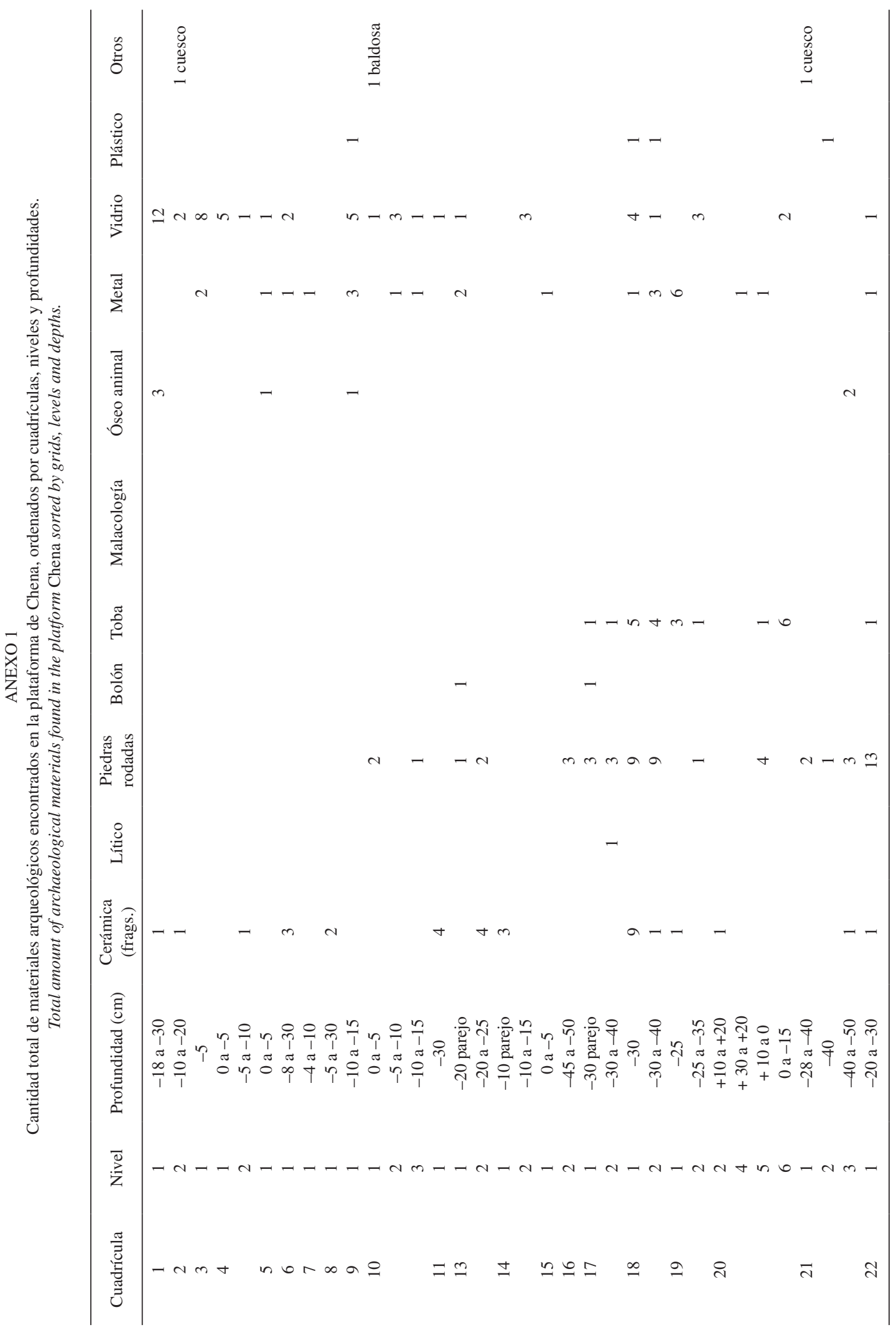




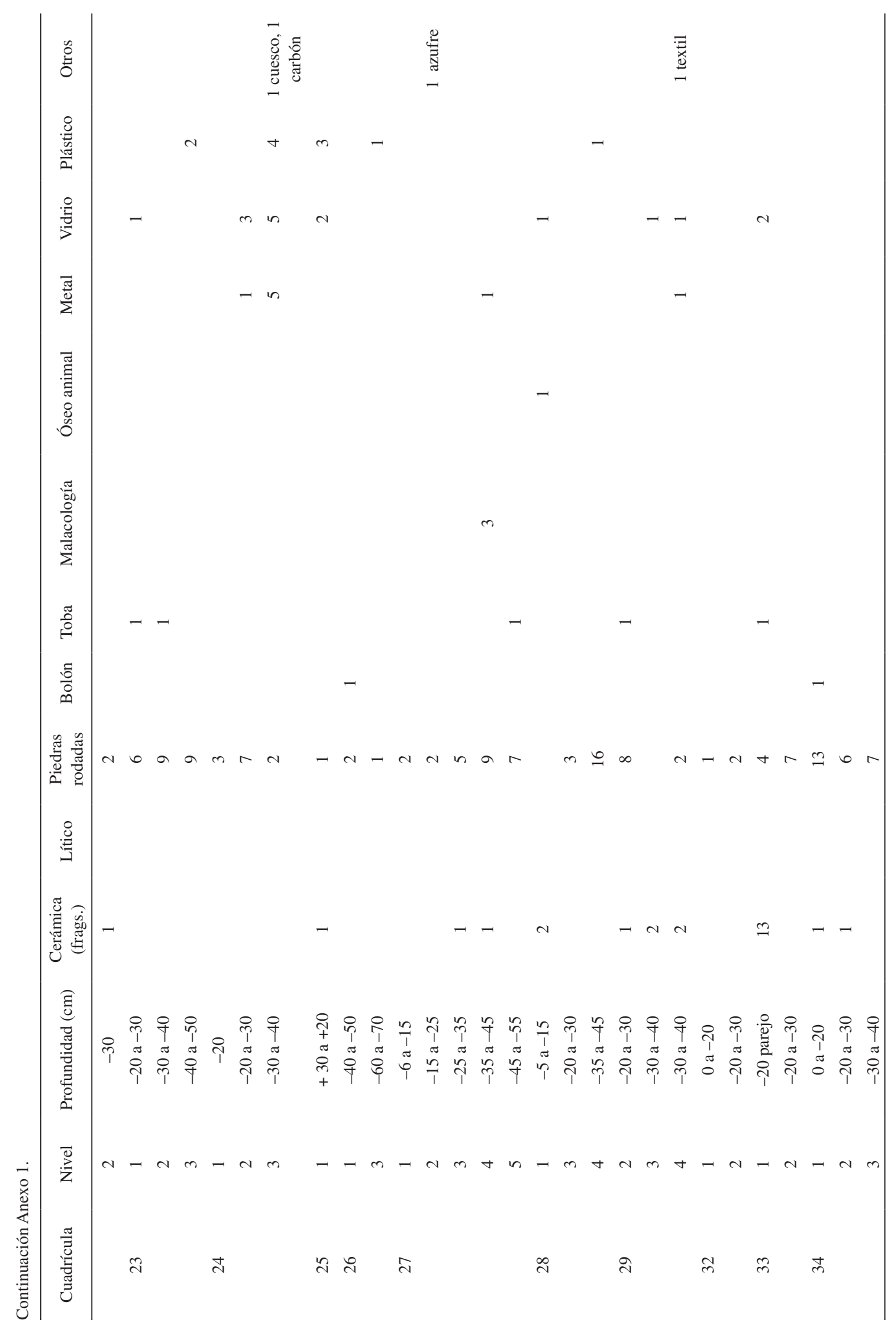




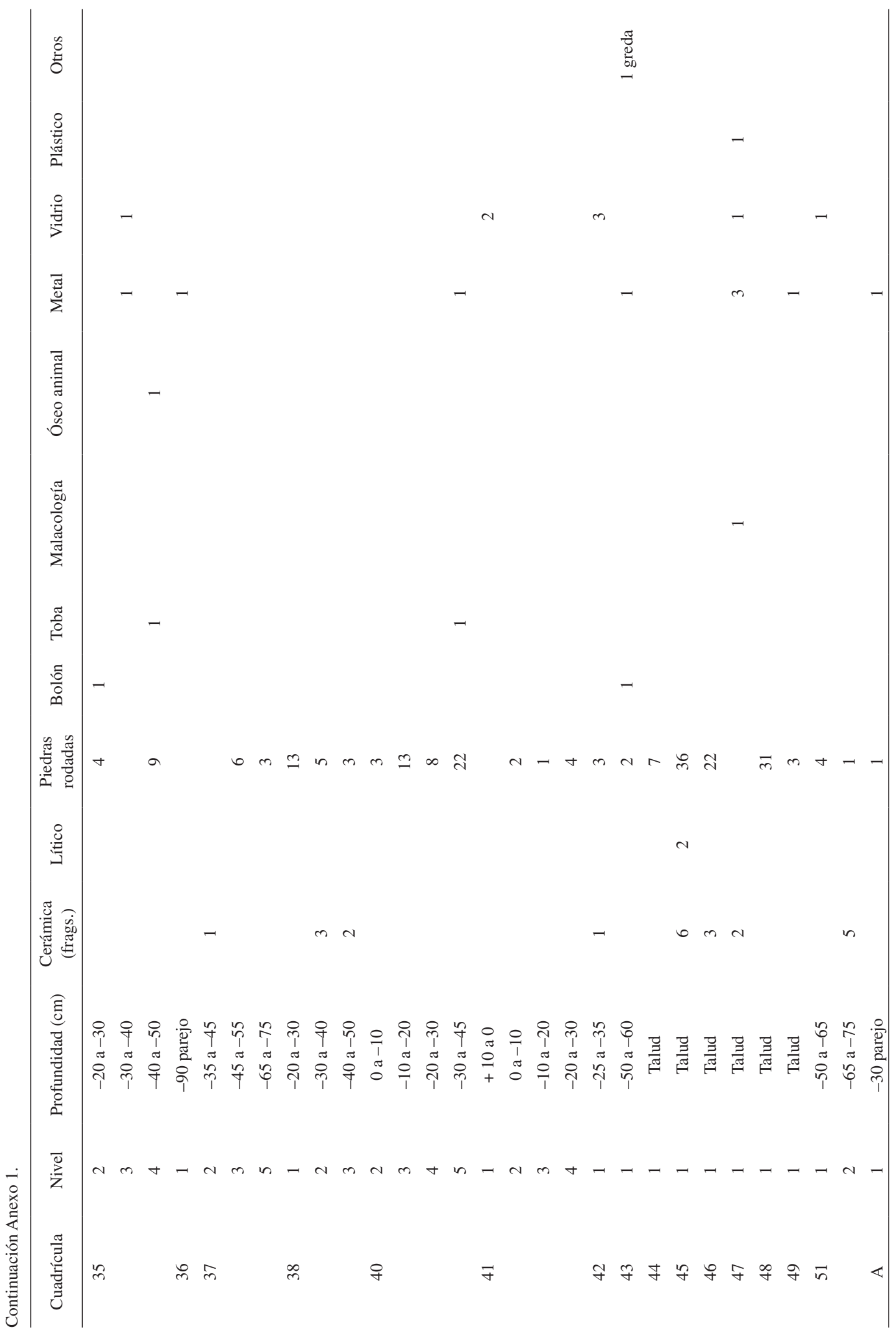




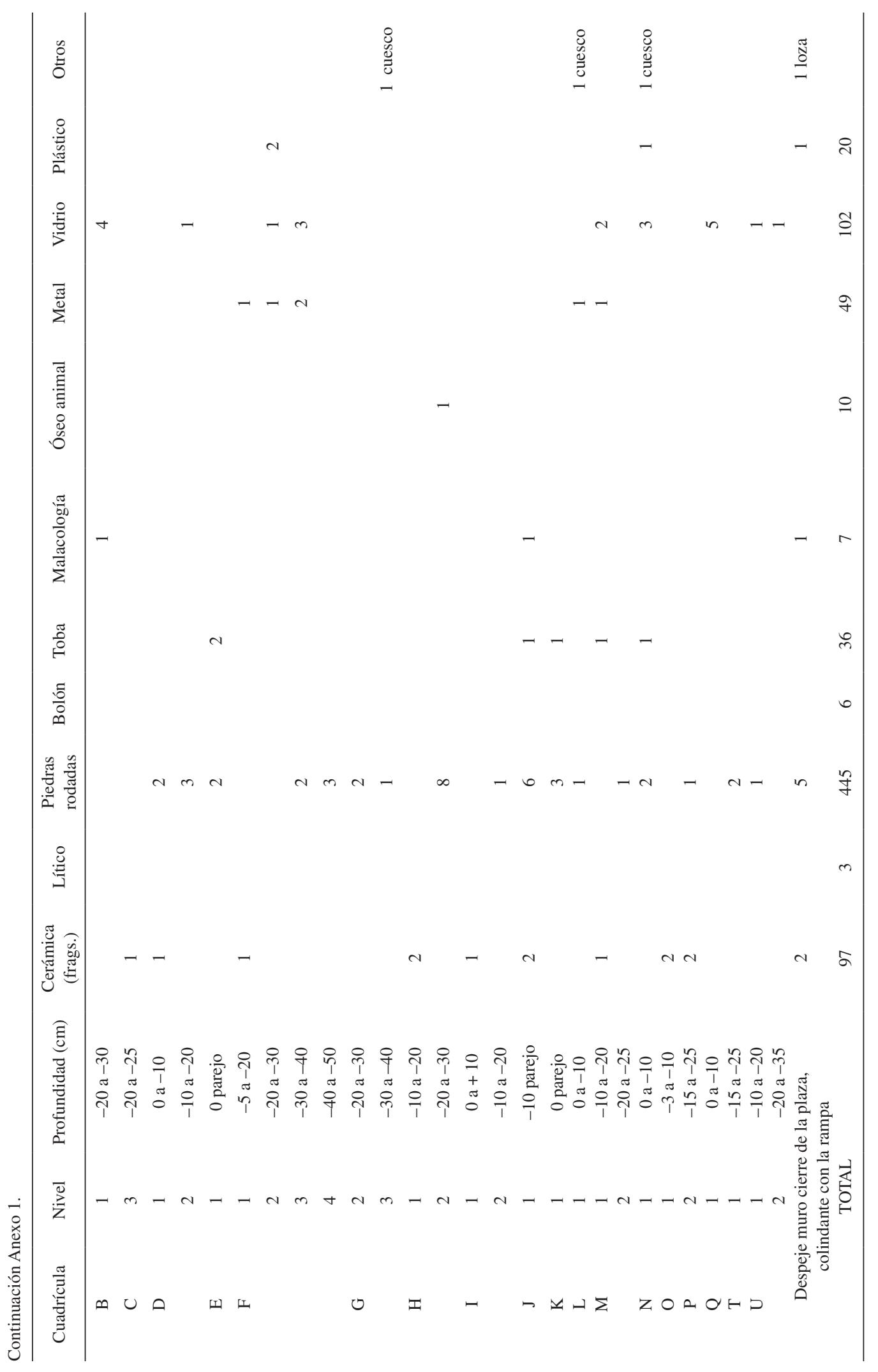

